\title{
ABSORBING AEROSOLS WORKSHOP JANUARY 20-21, 2016
}

\author{
Organizers: \\ Shaima Nasiri, Atmospheric System Research \\ Ashley Williamson, Atmospheric System Research \\ Co-chairs and Lead Writers: \\ Christopher D. Cappa, University of California \\ Davis Rao Kotamarthi, Argonne National Laboratory \\ Arthur J. Sedlacek, Brookhaven National Laboratory

\section{Contributing Writers:} \\ Connor Flynn, Pacific Northwest National Laboratory \\ Ernie Lewis, Brookhaven National Laboratory \\ Allison McComiskey, National Oceanic and Atmospheric Administration \\ Nicole Riemer, University of Illinois \\ Convened by \\ U.S. Department of Energy \\ Office of Science \\ Office of Biological and Environmental Research
}

July 2016

Environmental \& Climate Sciences Dept.

Brookhaven National Laboratory

\section{U.S. Department of Energy \\ USDOE Office of Science (SC), \\ Biological and Environmental Research (BER) (SC-23)}

Notice: This manuscript has been authored by employees of Brookhaven Science Associates, LLC under Contract No. DESC0012704 with the U.S. Department of Energy. The publisher by accepting the manuscript for publication acknowledges that the United States Government retains a non-exclusive, paid-up, irrevocable, world-wide license to publish or reproduce the published form of this manuscript, or allow others to do so, for United States Government purposes. 


\section{DISCLAIMER}

This report was prepared as an account of work sponsored by an agency of the United States Government. Neither the United States Government nor any agency thereof, nor any of their employees, nor any of their contractors, subcontractors, or their employees, makes any warranty, express or implied, or assumes any legal liability or responsibility for the accuracy, completeness, or any third party's use or the results of such use of any information, apparatus, product, or process disclosed, or represents that its use would not infringe privately owned rights. Reference herein to any specific commercial product, process, or service by trade name, trademark, manufacturer, or otherwise, does not necessarily constitute or imply its endorsement, recommendation, or favoring by the United States Government or any agency thereof or its contractors or subcontractors. The views and opinions of authors expressed herein do not necessarily state or reflect those of the United States Government or any agency thereof. 


\section{Biological and Environmental Research Climate and Environmental Sciences Division Absorbing Aerosols Workshop January 20-21, 2016}

Convened by

U.S. Department of Energy

Office of Science

Office of Biological and Environmental Research

Organizers:

Shaima Nasiri, Atmospheric System Research

Ashley Williamson, Atmospheric System Research

Co-chairs and Lead Writers:

Christopher D. Cappa, University of California, Davis

Rao Kotamarthi, Argonne National Laboratory

Arthur J. Sedlacek, Brookhaven National Laboratory

Contributing Writers:

Connor Flynn, Pacific Northwest National Laboratory

Ernie Lewis, Brookhaven National Laboratory

Allison McComiskey, National Oceanic and Atmospheric Administration

Nicole Riemer, University of Illinois 


\section{Executive Summary}

A workshop was held at DOE Headquarters on January 20-21, 2016 during which experts within and outside DOE were brought together to identify knowledge gaps in modeling and measurement of the contribution of absorbing aerosols (AA) to radiative forcing. Absorbing aerosols refer to those aerosols that absorb light, whereby they both reduce the amount of sunlight reaching the surface (direct effect) and heat their surroundings. By doing so, they modify the vertical distribution of heat in the atmosphere and affect atmospheric thermodynamics and stability, possibly hastening cloud drop evaporation, and thereby affecting cloud amount, formation, dissipation and, ultimately, precipitation. Deposition of AA on snow and ice reduces surface albedo leading to accelerated melt. The most abundant $A A$ type is black carbon (BC), which results from combustion of fossil fuel and biofuel. The other key AA types are brown carbon ( $\mathrm{BrC})$, which also results from combustion of fossil fuel and biofuel, and dust (crustal material). Each of these sources may result from, and be strongly influenced by, anthropogenic activities. The properties and amounts of AA depend upon various factors, primarily fuel source and burn conditions (e.g., internal combustion engine, flaming or smoldering wildfire), vegetation type (in the case of $\mathrm{BC}$ and $\mathrm{BrC}$ ), and in the case of dust, soil type and ground cover (i.e., vegetation, snow, etc.). After emission, AA undergo chemical processing in the atmosphere that affects their physical and chemical properties. Thus, attribution of sources of $A A$, and understanding processes $A A$ undergo during their atmospheric lifetimes, are necessary to understand how they will behave in a changing climate.

Three questions guided the workshop:

What are the most important underlying knowledge gaps regarding AA that limit our understanding of them and their roles in climate-relevant radiative, thermodynamic, and dynamic processes in the atmosphere?

- What factors currently limit a robust representation of AA properties and processes in large-scale models?

- How may these knowledge gap(s) be addressed with current and feasible new DOE resources, including observations from the Atmospheric Radiation Measurement (ARM) facility? What specific additional resources would be appropriate, and what value would be added by them?

A number of topical research areas that the DOE-ASR program is well positioned to address were identified: (i) characterization of the direct radiative forcing by $A A$ and attribution of forcing to aerosol type (e.g., BC, BrC, dust); (ii) improvement of measurement and retrieval of AA; (iii) representation of $A A$ properties and processes within models (iv) properties and evolution of $A A$ from biomass burning; and $(v)$ the impacts of $A A$ on atmospheric dynamics, thermodynamics, and circulation; cloud formation and lifecycle; and the hydrological cycle. The science questions behind each of these topical areas, along with key research activities that will address these questions, were proposed that involved laboratory studies, field measurements, and modeling activities.

Finally, the synergy between the ARM measurement and the ASR science programs was recognized as a unique and powerful combination of complementary capabilities that will ensure that DOE will continue to actively contribute to absorbing aerosol climate science and will remain a leader in this area. 


\section{Contents}

Executive Summary

1.0 Introduction

2.0 Workshop on Absorbing Aerosols

3.0 Workshop Discussion

4.0 Summary

5.0 References

Appendix A - Workshop Agenda

Appendix B - Workshop Organizers and Participants

Appendix C - Acronyms

\section{Introduction}

The U.S. Department of Energy (DOE) Climate and Environmental Sciences Division (CESD) aims to advance the development of robust predictive understanding of Earth's climate and environmental systems to inform the development of sustainable solutions to U.S. energy and environmental challenges. Within this framework, the DOE Atmospheric System Research (ASR) program supports activities that will advance process-level understanding of the interactions among and between aerosols, clouds, precipitation, radiation, dynamics and thermodynamics, and that can ultimately serve to reduce uncertainties in radiative forcing of climate.

\subsection{Background}

Atmospheric aerosols exert a large influence on Earth's climate. The role of atmospheric aerosols in radiation and cloud processes is complex and the quantitative impacts of aerosols have many uncertainties. Through their ability to absorb and scatter radiation (direct effect) and alter cloud properties (indirect effect), aerosols influence the global radiation budget and thermodynamic balance of the planet, and consequently global climate. This influences of aerosols on climate from aerosol-radiation interactions (ARI) and cloud-aerosol interactions $(\mathrm{ACl})$ are characterized by their radiative forcing, which can lead to either warming or cooling on local, regional or global scales. In addition, these interactions can lead to changes in the hydrological cycle. Radiative forcing by aerosols can act in concert with, but often opposes, the radiative forcing by greenhouse gases. The response of the Earth system to the combined forcing by aerosols and greenhouse gases is a key factor that determines the magnitude and impacts of current climate change. 
The net contribution of anthropogenic aerosols to radiative forcing from 1750 to the present is estimated by the Fifth Assessment Report of the Intergovernmental Panel on Climate Change (IPCC AR5) to be strongly negative $\left(-0.9 \mathrm{~W} / \mathrm{m}^{2}\right)$, but with a wide uncertainty range $(-1.9$ to -0.1 $\left.\mathrm{W} / \mathrm{m}^{2}\right)$. This can be compared with the much more certain net radiative forcing by greenhouse gases of $+3.2 \mathrm{~W} / \mathrm{m}^{2}\left(+2.6\right.$ to $\left.+3.8 \mathrm{~W} / \mathrm{m}^{2}\right)$. The contributions to the net radiative forcing by aerosols from $A R I$ and $A C I$ have been assessed separately. Both are negative, with the net $A R I$ forcing estimated to be $-0.23 \mathrm{~W} / \mathrm{m}^{2}\left(-0.77\right.$ to $\left.+0.23 \mathrm{~W} / \mathrm{m}^{2}\right)$ and the net $\mathrm{ACl}$ forcing to be -0.55 $\mathrm{W} / \mathrm{m}^{2}\left(-1.33\right.$ to $\left.-0.06 \mathrm{~W} / \mathrm{m}^{2}\right)$. Thus, the substantial uncertainties in both the net ARI and ACI radiative forcings dominate the uncertainty in the total radiative forcing from aerosols and greenhouse gases. This large uncertainty limits the extent to which the modern day forcingtemperature response relationships and the spatial variability of this relationship are understood, and challenges predictions of the impacts of future climate change on, among other factors, global temperatures and the hydrologic cycle.

One particular class of aerosols, light-absorbing aerosols, continue to contribute substantially and disproportionately to this net uncertainty in aerosol forcing despite their small relative abundances compared to non-absorbing aerosol types. Their importance and influence on climate are directly determined by their ability to absorb solar radiation, both in the atmosphere and after their deposition to the surface, and by the substantial redistribution of energy in the atmosphere that results from this absorption. Previous studies have identified three main aerosol types that absorb solar radiation: black carbon $(\mathrm{BC})$, brown carbon $(\mathrm{BrC})$, which is a subset of organic aerosol (OA), and mineral dust. Together, these absorbing aerosols will be referred to as $A A$, although each is distinct in terms of its sources and distribution in the atmosphere. These AA result from both anthropogenic and natural activities and sources. Quantifying the radiative impact of AA separately from other aerosol types has proven challenging [Bond et al., 2013; IPCC, 2013]. BC and mineral dust are directly emitted into the atmosphere and can undergo additional chemical and physical transformations. Key sources of $\mathrm{BC}$ are fossil fuel combustion, cooking, industrial processes, and biomass burning [Bond et al., 2004]. BrC can be emitted directly as primary organic aerosol (POA), of which organic material in biomass burning is a significant source, but it can also be produced through secondary organic aerosol (SOA) formation and transformation via chemical reactions in the atmosphere. Mineral dust is emitted primarily from wind action over arid regions.

The influence of each of these absorbing aerosol types on the climate system varies over a range of temporal (hourly to daily to seasonally) and spatial (local to regional to global) scales, and can change as AA undergo chemical processing in the atmosphere. Both the properties and amounts of AA are affected by various factors such as fuel source and burn conditions, vegetation type (in the case of $\mathrm{BC}$ and $\mathrm{BrC}$ ), and in the case of dust, soil type and ground cover (i.e., vegetation, snow, etc.). Each of these aerosol types is produced directly by anthropogenic activities, such as industrial combustion, as well as by natural activities. Production of each aerosol type is also indirectly affected by anthropogenic activities such as land use changes that, for example, make biomass burning (i.e., forest fires) or surface dust exposure more prevalent. Climate forcing by AA (both from anthropogenic and perturbed natural sources) occurs on top of a natural, background state. To understand and quantify absorbing aerosol effects on and responses to a changing climate, attribution of their sources and understanding of the processes that transform them during their atmospheric lifetimes are necessary. 
The net radiative forcing by absorbing aerosols is generally positive (warming), and results from a variety of specific effects and are impacted by different atmospheric processes, illustrated in Figure 1. AA typically suppresses the overall cooling impacts of $A R I$ and $A C I$ on both global and regional scales. Compared with greenhouse gases, the concentrations of aerosols in general, and those of AA in particular, vary greatly spatially and temporally due to their formation mechanisms (e.g., forest fires) and comparably short atmospheric lifetimes (days to weeks). Thus, the regional forcing by aerosols can be dramatically different than the global average, even differing in sign. It is important to recognize, however, that a net forcing near zero does not imply that the net effect of aerosols is near zero, as $\mathrm{BC}, \mathrm{BrC}$, and dust affect different processes in the atmosphere at different vertical/horizontal spatial and temporal scales.

Because of the importance of AA on climate, it is crucial to develop a predictive understanding of their properties and life cycles to characterize and quantify their specific roles in Earth's radiative budget, the hydrological cycle, the cryosphere, atmospheric dynamics, and climate. Activities that lead to improved knowledge and parameterization of AA must include instrument development and targeted laboratory studies to understand the processes and factors that control the properties and atmospheric lifetimes of AA. Specific examples are surface- and aircraft-based field studies to investigate the evolution of AA abundances and properties from different sources, remote sensing to extend these laboratory and field studies to larger regions (including global), and modeling studies at all scales to test and integrate our understanding of these various aspects of AA and their climate impacts. 


\section{incoming solar \\ radiation}
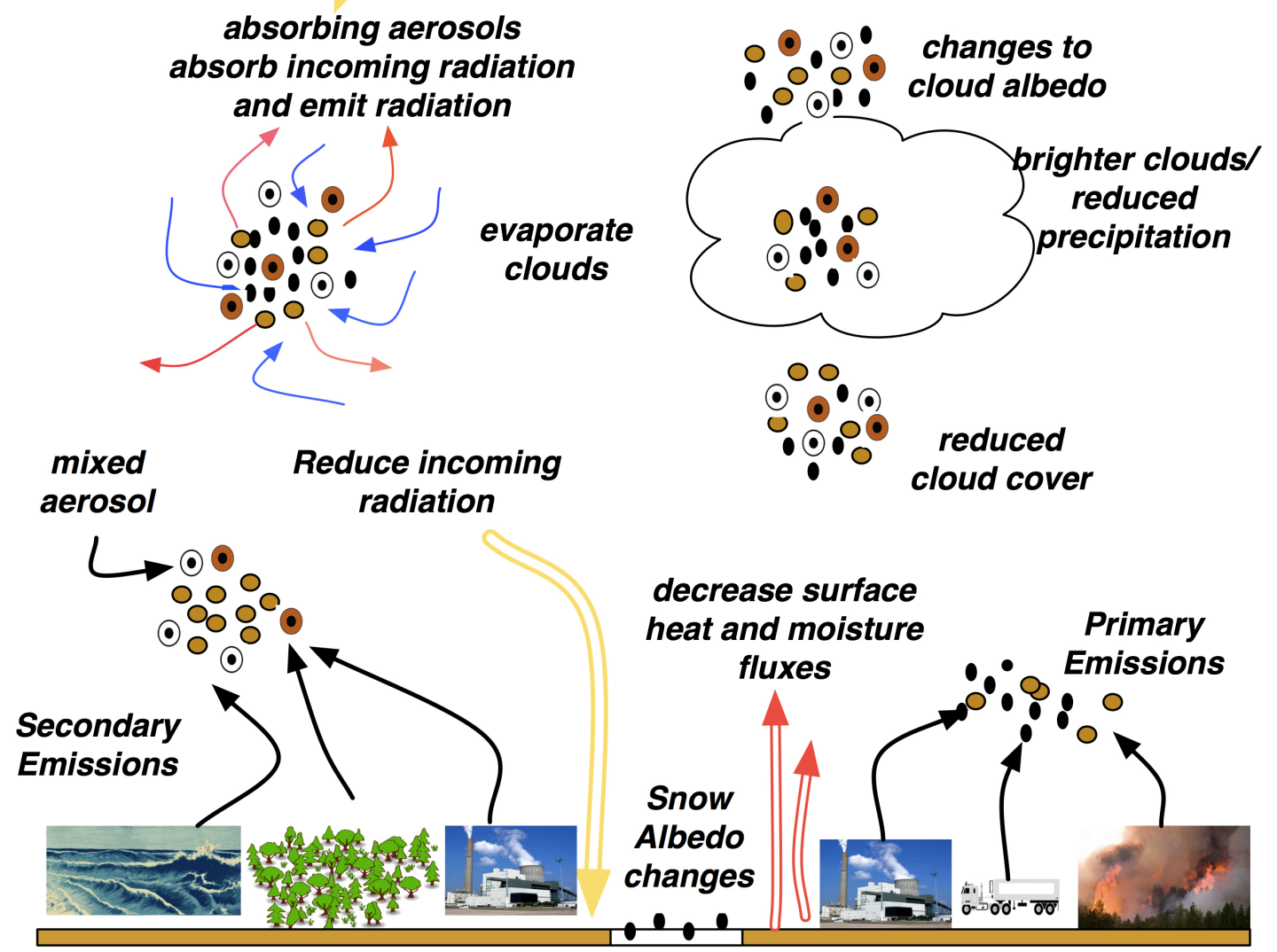

Figure 1: Absorbing aerosols in the atmosphere and the various ways they interact with incoming solar radiation, clouds, and the dynamic and thermodynamic state of the atmosphere.

\subsection{State of Absorbing Aerosol Understanding}

Absorbing aerosols impact climate by directly absorbing solar radiation inside and outside of clouds or after deposition onto bright surfaces, especially snow and ice. Absorption by AA can lead to a reduction of solar radiation to the surface, warming of atmospheric layers, and darken of bright surfaces (ice and snow) on which AA is deposited. These processes can lead to changes in cloud properties and cloud cover, surface heat and moisture fluxes, melt rates of snow and ice, and overall atmospheric stability. The different AA types each exert a distinctive control on the global radiation and energy budget due to differences in their atmospheric distributions (both vertically and horizontally), mixing state and morphology, lifetimes, and their intrinsic ability to absorb or scatter radiation of different wavelengths. General understanding of 
the three major $\mathrm{AA}$ types (BC, $\mathrm{BrC}$ and dust) and their characterization along with gaps in this understanding, are summarized briefly below.

\subsubsection{AA Types}

Black Carbon: Of the three AA types, BC is an especially strong absorber of solar radiation and is unique in its ability to absorb light across the entire solar spectrum. The absorptivity of pure BC is fairly well established, and depends on the morphology (compactness) of the BC particle, although uncertainties remain regarding the exact spectral dependence. Further, the effective absorptivity of $\mathrm{BC}$ is dependent upon the extent to which it is internally mixed with other aerosol components (including water) and on the morphologies of the mixed particles, making this an evolving property in the atmosphere. Such mixing can enhance the absorptivity of $\mathrm{BC}$, thereby increasing its climate impacts. Enhancement of $\mathrm{BC}$ absorption by absorbed materials on BC-containing particles has been demonstrated in laboratory studies. However, ambient measurements of the magnitude of the enhancement and the dependence of the enhancement on mixing with other components and on morphology have given conflicting results, and the influence of water and the morphology of the mixed particle are undercharacterized. Unmixed BC is hydrophobic, but BC becomes more hydrophilic as it mixes with other aerosol components. Understanding the processes and factors that drive atmospheric variability in $\mathrm{BC}$ absorption and properties, both in and out of clouds, is a critical need, so that robust model parameterizations of the $\mathrm{ARI}$ and $\mathrm{ACl}$ and associated thermodynamic feedbacks can be developed.

A recent comprehensive assessment of the ARI forcing by $B C$ found that the magnitude of solar absorption by $B C$ in many models is lower than estimates derived from remote sensing of the aerosol absorption optical depth (AAOD) by roughly a factor of three [Bond et al., 2013]. This difference results from uncertainties in $B C$ emission inventories, atmospheric lifetime, vertical distributions, intrinsic absorptivity, and the ability to confidently apportion AAOD into contributions from $\mathrm{BC}, \mathrm{BrC}$ and dust. After increasing $\mathrm{BC}$ absorption in models to agree with observations, the $A R I$ radiative forcing of $B C$ was estimated to be strongly positive, but highly uncertain, and equal to $+0.71 \mathrm{~W} / \mathrm{m}^{2}\left(+0.08\right.$ to $\left.+1.27 \mathrm{~W} / \mathrm{m}^{2}\right)$. Although such a posteriori model tuning (scaling), as in Bond et al. [2013], can potentially allow for improved estimates of the climate effects of BC specifically, and AA in general, there is a substantial concern that the improved agreement is being obtained for incorrect reasons and masks real uncertainties in the processes that contribute to the model/observation mismatch. The combined net radiative forcing of $\mathrm{BC}$ from $\mathrm{ARI}$ and $\mathrm{ACl}$ effects is even more positive, with an even wider uncertainty range: $+1.1 \mathrm{~W} / \mathrm{m}^{2}\left(+0.17\right.$ to $\left.+2.1 \mathrm{~W} \mathrm{~m}^{-2}\right)$. Reducing this range of uncertainties presents a large, yet important, challenge.

Brown Carbon: The primary characteristic of $\mathrm{BrC}$, or absorbing organic carbon (OC), is the strong wavelength dependence of the absorptivity, with absorptivity increasing rapidly with decreasing wavelength from the mid-visible through the ultraviolet range. A key challenge in understanding the climate impacts of $\mathrm{BrC}$ is that unlike $\mathrm{BC}, \mathrm{BrC}$ is not one chemical component, but rather a mixture of individual organic compounds that have a range of individual properties. Further, $\mathrm{BrC}$ is chemically reactive, both being formed and degraded over time in the 
atmosphere. As such, the optical properties of BrC remain highly uncertain--and highly variable-thus limiting accurate estimation of $\mathrm{BrC}$ forcing from models. The absorptivity of $\mathrm{BrC}$ tends to be much lower than that of $\mathrm{BC}$ even at shorter wavelengths (where the absorptivity of $\mathrm{BrC}$ is increasing rapidly). However, because $\mathrm{OA}$ is typically much more abundant than $\mathrm{BC}$, the total absorption by $\mathrm{BrC}$ can nonetheless be substantial, and recent studies indicate that $\mathrm{BrC}$ forcing can be significant and even comparable to BC forcing in some regions [Feng et al., 2013]. Understanding the diversity in $\mathrm{BrC}$ properties, emissions, and susceptibility to chemical transformation between sources is a key need.

Dust: Mineral dust absorbs moderately in the visible and long wavelengths, with an absorptivity that depends on the dust source. Dust is distinct from $\mathrm{BC}$ and $\mathrm{BrC}$ in that the bulk of the emissions by mass are associated with particles with diameters greater than one micrometer. Consequently, the atmospheric lifetime tends to be shorter than those of BC and $\mathrm{BrC}$, although dust can still undergo interhemispheric transport and thus be of both regional and global importance. Recent satellite data analysis suggests that Saharan dust may induce radiative heating on the order of $2-4 \mathrm{~K}$ in the transatlantic dust layer [Davidi et al., 2012]. The estimated global radiative forcing of dust is about $-0.1 \mathrm{~W} \mathrm{~m}^{-2}$ with an uncertainty range of -0.3 to $+0.1 \mathrm{~W} \mathrm{~m}^{-2}$ [IPCC, 2013].

\subsubsection{AA Measurement Characterization}

Observational methods for characterization and quantification of AA can generally be categorized into passive remote sensing, active remote sensing, and in situ. Passive remote sensing methods provide regional or even global assessment of AA column burdens, whereas active remote sensing and in situ methods provide detailed information on (typically) smaller spatial scales.

Passive remote sensing of aerosol abundance and properties can be conducted from the surface, aircraft, or satellite, and they provide column-integrated (or line-of-sight) values of aerosol optical depth (AOD). They can also provide values of AAOD or single scatter albedo (SSA) when signal levels are sufficiently large. Surface-based networks of passive sun photometers (such as AERONET, SKYNET, and those in ARM) provide semi-continuous characterization of aerosol and atmospheric properties during daytime under cloud-free conditions. Satellite retrievals of AA properties (from e.g. OMI and OMAERUV) provide similar information to those provided by the surface-based networks, but at the global scale for cloudfree regions. Thus, passive remote sensing can provide a picture of the vertically integrated, temporally varying spatial distribution of $A A$, but with significant limitations from the perspective of informing/improving models. Specifically, passive retrievals do not provide information on vertical structure, have difficulty in apportioning $\mathrm{AA}$ absorption among $\mathrm{BC}, \mathrm{BrC}$, and mineral dust, are not able to distinguish traits such as morphology or mixing state, and typically require high aerosol loadings. This last issue raises concerns of the representativeness of AAOD retrievals from AERONET, despite its broad spatial coverage with hundreds of sites distributed around the world. In contrast, SKYNET and ARM employ instrument techniques and retrievals applicable to lower aerosol burdens but have much less comprehensive spatial coverage. 
Active remote sensing of aerosols by surface-based sophisticated multi-wavelength lidar (EARLINET, CHARMS at ARM SGP) and aircraft (NASA Langley, SSEC U.W.) allows determination of vertically resolved (as opposed to column integrated) profiles of extinction and SSA, as well as rudimentary determination of particle shape (allowing inference of mineral dust). However, active remote sensing retrievals are also limited in their ability to ascertain particle morphology (beyond asphericity) and mixing state, and to apportion AA into constituent types, especially within a given particle size range. More generally though, both the passive and active retrievals suffer as compared to direct in situ measurements from a lack of comprehensive assessment of aerosol properties within the atmospheric column.

In situ methods allow for characterization of aerosol properties at a single location, which may be either fixed at the surface or on a mobile platform (e.g., aircraft, ships), and sample only at the location of the platform. This characterization may be performed in real time or may involve sample acquisition and subsequent laboratory analysis. Continuous in situ measurements at fixed locations (e.g., the DOE ARM Southern Great Plains (SGP) site, North Slope of Alaska (NSA), and several mobile deployments of 1-2 years) have been used to develop understanding of long-term trends. Additionally, when collected at relatively high temporal resolution, such measurements can be used for characterization over shorter time periods (weeks to a few months) to develop process-level understanding. Process studies benefit most from co-located measurements of a range of aerosol properties, such as size distribution, chemical composition, and optical properties. Critically though, in situ methods whether at the surface or from aircraft - are still challenged to provide measurements of the optical properties of ambient AA with the accuracy necessary to assess or validate the remote sensing retrievals.

\subsubsection{AA Model Characterization}

Observations indicate that ambient aerosol populations exhibit much greater compositional and morphological complexity than are currently accounted for in regional and global models, due to computational constraints and gaps in process-level understanding. Aerosol models necessarily make simplifying assumptions, which ultimately impact the calculation of optical properties, including absorption. A modeling framework used in many global models is to approximate the aerosol size distribution by several overlapping log-normal modes with particle size as the independent variable. Typically, number and mass concentrations of a mode are allowed to vary, but the width of the mode is held constant. An inherent assumption of this approach is that each mode is "internally mixed", meaning that all particles within a given mode have the same composition, which is equal to the average composition of the mode.

Compositional differences within the population can be resolved to some extent by having several modes, even within a given size range, with aerosol aging represented by allowing interactions between modes. For example, the Modal Aerosol Model in CAM (MAM4) uses four modes to represent the aerosol population: an Aitken, accumulation and coarse mode, each of which contain different aerosol species as internal mixtures, and a fourth mode that contains freshly emitted carbonaceous aerosol (BC and $\mathrm{OC}$ ). Carbonaceous aerosol can "age" from the fresh mode to the internally mixed accumulation mode, and only the internally mixed modes are 
subject to removal by wet deposition. Calculation of optical properties of particles within a mode requires additional assumptions regarding article shape and morphology. It is commonly assumed that particles are spherical and optical properties are calculated using Mie theory. When $\mathrm{BC}$ is present, a core-shell morphology is typically assumed, with BC forming the core, and the other material forming the coating. However, it is known from observations that the optical properties of BC-containing particles do not necessarily conform to a core-shell morphology, and thus it is unclear when and under what conditions such an assumption is justified [Cappa et al., 2012].

It is currently an open research question how much error the various assumptions (regarding size, composition/mixing state, particle shape/morphology) introduce to estimates of the aerosol impact on climate in general, and of aerosol absorptivity in particular. A recent study [Kaiser et al., 2014] shows, for example, that large discrepancies can exist between the simulated size distributions of a modal model (MADE3) and a particle-resolved, "benchmark" model (PartMCMOSAIC). Such discrepancies in size distribution and mixing state will then propagate into the calculation of optical properties. In addition to these "immediate" impacts of errors in aerosol population on optical properties, there are indirect ways that details of aerosol aging may affect estimates of aerosol absorption, such as the dependence of wet scavenging of BC on its mixing state.

\section{Workshop on Absorbing Aerosols}

Recognizing the importance of absorbing aerosols to global climate, DOE BER organized a workshop to discuss the radiative effects of absorbing aerosols and obtain guidance from experts to identify knowledge gaps that currently limit our ability to resolve some of the questions and reduce uncertainties. The workshop was held on January 20-21, 2016 at Germantown, Maryland. A description of the workshop agenda and breakout groups that led to the development of this report is provided in Appendix A. Prior to the workshop, the organizers solicited input from the attendees in the form of white papers, submitted 2 weeks prior to the workshop, in response to three guiding questions:

Question 1: What are the most important underlying knowledge gaps regarding absorbing aerosols that limit our understanding of these species and their roles in climate-relevant radiative, thermodynamic, and dynamic processes in the atmosphere?

Question 2: What factors currently limit a robust representation of these absorbing aerosol processes in large-scale models?

Question 3: How may these knowledge gap(s) be addressed with current and feasible new DOE resources, including observations from the Atmospheric Radiation Measurement (ARM) facility? What specific additional resources would be appropriate, and what value would be added by them? 
This report summarizes the primary scientific challenges and high priority research topics identified during the workshop and in the solicited white papers.

\subsection{Workshop Discussion}

\subsection{Overview of Science Themes}

\section{Scientific controversies, challenges, and opportunities in understanding AA contribution to forcing}

Workshop attendees concluded that uncertainties in estimates of the radiative forcing by AA (due to both $\mathrm{ARI}$ and $\mathrm{ACl}$ ), and in cloud and atmospheric responses to the distribution of $\mathrm{AA}$ in the atmosphere, can be reduced by advances and activities in a number of areas. Key challenges for reducing these uncertainties were identified as: (i) limitations associated with point measurements and with remote sensing and retrieval; (ii) making meaningful extrapolations from sparse measurements; and (iii) development and evaluation of models at the spatial and temporal scales that capture AA lifecycle processes (generation, transformation, transport, and removal). Based on these challenges, the following critical themes and motivating questions were identified during the workshop:

- What are the contributions of black carbon, brown carbon, and dust to aerosol absorption across the solar and terrestrial spectrum and how do these vary with atmospheric conditions (e.g. RH)? How can these contributions be attributed to source (e.g., natural vs. anthropogenic)? How might these contributions change in a changing climate?

- There are large model/measurement discrepancies in ARI forcing by BC. Measurements of AAOD utilizing existing surface-based remote sensing networks (AERONET, SKYNET, ARM) also include contributions from $\mathrm{BrC}$ and dust, which must be subtracted to quantify $B C$ specifically. What are the contributions to these discrepancies from uncertainties/inaccuracies in the measurements, in AAOD separation (BC vs. BrC vs. dust), and in $B C$ inventories, versus those that are intrinsic to the models (e.g., transport, aging timescales, relating concentration to absorption)? Can these discrepancies be reduced with current in situ techniques?

- What are the spatial and temporal scales necessary to accurately capture AA processes? What is the best way to represent AA size distributions, optical and microphysical properties, and their evolution in models? What is the best way to represent $A A$ size distributions, optical and microphysical properties, and their evolution in models? To what extent are model/measurement discrepancies due to model representation vs. measurement uncertainty? What factors govern the vertical distribution of AA on local and regional scales? 
- Combustion of biomass and biofuels is a major source of AA. However, other co-emitted species can alter the optical properties, lifecycle, and thus net forcing from AA. What factors and processes control the net radiative effects of AA? How do these factors and processes vary by region and across scales? How might they behave in a changing climate?

- Given the unique ability of AA to redistribute energy through the atmospheric column via localized heating from absorption, what are the impacts of AA on atmospheric thermodynamics, atmospheric circulation, and surface-atmosphere feedbacks (especially cloud responses)? How might these responses change in a changing climate? How do these impacts affect the hydrological cycle, both regionally and globally? What are the impacts of surface albedo change due to deposition of AA and how might this change in the changing climate?

The above issues illustrate that development of a detailed understanding of the fundamental processes and associated physical, chemical, and optical properties of absorbing aerosols, and their effects on the dynamics and thermodynamics of the atmosphere, including landatmosphere and ocean-atmosphere feedbacks, is critical. Improved understanding remains necessary to reduce the uncertainty in both $A R I$ and $A C I$ radiative forcing and feedbacks due to greenhouse warming in the current climate and for evaluating the anthropogenic influence on climate change over the past several hundred years and into the future. The following sections address ways identified by workshop participants that ASR is uniquely situated to address the above issues.

\subsection{Improving Understanding of Absorbing Aerosols and their Climate Impacts}

\section{Topical areas that leverage ASR strengths/expertise}

\subsubsection{Direct Radiative Forcing from AA}

Development of an observationally constrained global picture of AA burdens and properties (e.g., apportionment) is necessary to fully quantify AA radiative effects and understand how these will change into the future. This picture can be obtained by integrating in situ and remote sensing observations. It was concluded that a high-value activity in this area would be a targeted effort to improve surface-based measurements, both in situ and remote sensing, culminating in a field study at an appropriate location. Key considerations as to location are the likelihood of encountering mixed AA sources and particle types, expected signal levels of sufficient magnitude that the AOD threshold for AERONET level 2 AAOD retrievals will be exceeded on a regular basis (it was suggested that preference be given to locations where the discrepancy between AERONET and satellite retrievals or between AERONET and models is large), the extent to which the campaign will complement and take advantage of existing long- 
term data records, and logistical issues surrounding deployment. Several ARM DOE fixed sites (the Southern Great Plains site in north-central Oklahoma, the North Slope site in Alaska, and the recently-established Eastern North Atlantic site on Graciosa Island in the Azores) have both in situ surface measurements and sun photometer remote sensing measurements. There have also been several 1-2 year ARM mobile facility (AMF) deployments, but at locations that were intentionally in more remote regions. It was concluded that such a study should make use of one of the ARM mobile facilities and take place in a region where AAOD is routinely above the detection threshold. Additionally, selection of a region that is likely to be impacted by the different AA types with varying contributions would be important to development of AAOD apportionment methods.

For any deployment, in situ measurements should be made at both the surface and vertically through the atmosphere. The in situ vertical characterization should involve measurements from aircraft, and also potentially from smaller platforms such as unmanned aerial systems (UASs), including drones or tethered balloons. A key benefit of including aircraftbased measurements is that they can allow for a comparably large payload, facilitating the deployment and validation of state-of-the-science instrumentation for characterization of aerosol optical properties and composition for both quantification of abundances and the investigation of process-level relationships. A key benefit of including alternative, smaller-payload platforms (UAS) is that they potentially allow for greater temporal coverage, i.e. higher time resolution, although with decreases in sensitivity, accuracy, and capabilities.

Next-generation remote sensing techniques should be simultaneously deployed for covalidation and testing, in addition to more commonly used methodologies such as sun photometers, which form the basis of the AERONET network and the core of some global estimates of BC radiative effects [Bond et al., 2013] and improved retrievals combining complementary measurements from multiple sun photometers and radiometers. Additionally, continued use of multiple remote spectral methods, such as the combination of Raman lidar and high spectral resolution lidar (HSRL) measurements, should be made, as these may allow for retrieval of vertically-resolved aerosol absorption. Use of mobile AERONET-proxy methods, such as the Spectrometer for Sky-Scanning, Sun-Tracking Atmospheric Research (4STAR) instrument, can allow for regional-scale spatial profiling of AAOD and AOD during measurement campaigns and targeting of aloft aerosol layers, while collocated airborne measurements of spectral fluxes (up, down, and omni-directional) collected above and below aerosol layers offers potential for additional independent retrievals.

Key research activities identified by the workshop that can help address scientific gaps associated with quantification of the direct radiative impacts of absorbing aerosol are:

1. Retrieval validation. Assess the performance of current remote-sensing AAOD retrievals, especially those from AERONET because of its quasi-global coverage and current use in constraining both satellite retrievals and model results, through a targeted field study.

2. Attribution. Develop methodologies and techniques for the apportionment of the contributions of the different $A A$ types (BC, BrC and dust) to AAOD retrievals.

3. Enhanced AAOD retrievals. Develop next-generation AAOD retrieval methods having lower detection thresholds and the ability to provide vertical resolution in addition to column-average properties. 
4. Surface-Column relationships. Examine the extent to which surface in situ measurements of SSA are representative of the entire column, and how such relationships vary in time and space.

5. Vertical distribution development. Develop methodologies to determine the factors that govern the vertical distribution of AA on local and regional scales.

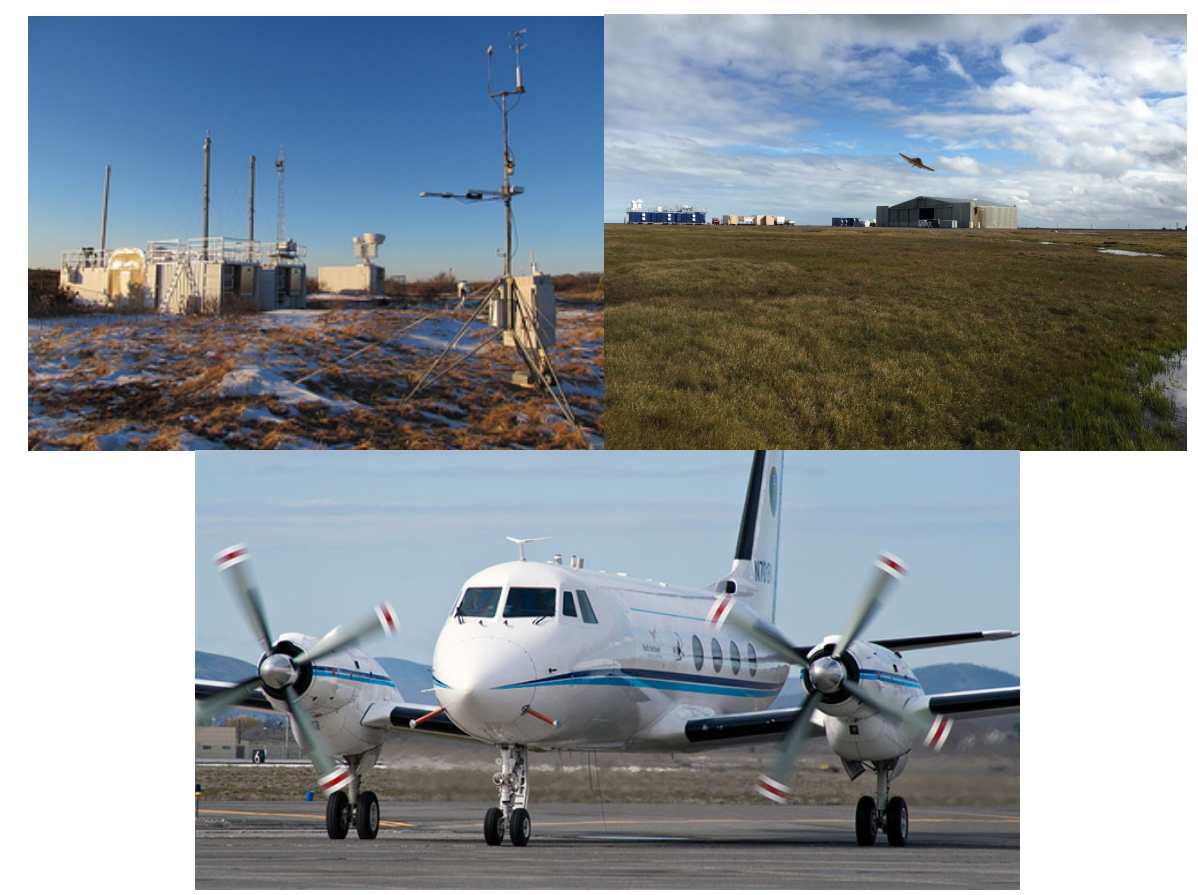

Figure 2. Top left: AMF1 (from ARM website). Top right: A DataHawk2 UAS flies over the AMF3 at Oliktok Point during the ERASMUS campaign in summer 2015. (from DOE ASR Website) Bottom: DOE Gulfstream-1 aircraft. (from BBOP press release)

\subsubsection{AA Measurement Needs}

The contributions from the several AA types will vary spatio-temporally due to variations in emissions and formation, transport, removal, and transformations. Apportionment and quantification of the contributions of the different $A A$ types to total absorption under various atmospheric conditions, including at elevated relative humidity, requires new measurement capabilities and analysis techniques (both in situ and remote sensing) that can characterize and quantify ambient AA properties and concentrations. As the accuracy of each measurement technique differs, it is necessary to establish the accuracy and/or precision that is required to address a particular science question. Modeling-based sensitivity studies could help to address measurement accuracy requirements. Brief discussion of current limitations and future opportunities regarding the measurement needs to address science questions associated with absorbing aerosols is provided below.

\subsubsection{In Situ Absorbing Aerosol Characterization}


Absorption Measurements: There exist a variety of methods to measure aerosol absorption, with a range of sensitivities, accuracies, and field deployment potential. Most existing methods measure absorption by dry particles, as the presence of liquid water can lead to difficult-toquantify measurement issues. Measurements from filter-based techniques, such as the particle soot absorption photometer (PSAP), form the core of long-term records, including those at ARM sites. The PSAP can be deployed at surface sites or on aircraft. Concerns have arisen regarding biases in the PSAP absorption measurements [Cappa et al., 2008; Lack et al., 2008; Subramanian et al., 2007] that have not yet been satisfactorily resolved. However, the ability to deploy the PSAP on aircraft allows for at least a qualitative understanding of the vertical variability in absorption. An additional concern is that production of the PSAP has been discontinued, thus impacting the long-term viability of this method even in the absence of potential biases, although the recent development of more compact sister instruments such as the tri-color absorption photometer (TAP) and the continuous light absorption photometer (CLAP) [Ogren et al., 2013], which are based on the same principle, may alleviate this concern to some extent. Given the importance of long-term records of absorption, it is necessary to understand the extent to which the ARM PSAP measurements have been biased and to correct for such biases. Additionally, understanding the dependence of measured absorption on relative humidity is required for meaningful interpretation of measurements from filter-based instruments deployed on UASs.

Measurement of absorption by suspended ambient particles, without deposition on a filter, provides a means to circumvent the bias issues that affect the PSAP. Photoacoustic and photothermal interferometric (PAS and PTI, respectively) measurements of suspended particle absorption have seen increased development and usage. Commercial instruments, such as the 3-wavelength photoacoustic absorption soot spectrometer (PASS-3) and single-wavelength photoacoustic eXtinctiometer (PAX) are now available. Although these instruments are well suited for measurement in areas where absorption levels are reasonably high, they are generally not as sensitive as research-grade (i.e., custom) instruments, and thus their performance in remote regions (such as the ARM SGP or BRW sites) has not been adequate. As a result, ARM has discontinued routine surface- and aircraft-based PASS-3 measurements. Custom PAS and PTI instruments have been deployed on aircraft platforms with variable results; they have successfully quantified absorption within biomass burning plumes, but further development is necessary if they are to be used to fully characterize vertical profiles from aircraft under a wide range of conditions and concentration levels. These instruments allow selection of the wavelengths of measurement through use of different lasers. Measurements are most-often made at $405 \mathrm{~nm}, 532 \mathrm{~nm}, 780 \mathrm{~nm}$ or $870 \mathrm{~nm}$, dictated in part by available laser technology. Other wavelengths have been used in research (non-commercial) applications, but the sensitivity has typically proven to be relatively low. Extension of the wavelength range into the ultraviolet is needed to understand the full impact of $A A$ across the solar spectrum, and would further facilitate attribution among different $A A$ types.

Light extinction is the sum of absorption and scattering. Therefore, absorption can be measured as the difference between extinction and scattering, both of which can readily be measured. Historically, extinction and scattering measurements were made using separate instruments, leading to substantial concerns about the accuracy of this "difference" method. 
Recently developed instrumentation, such as the aerosol albedometer [Thompson et al., 2008] or commercial cavity attenuated phase shift single scatter albedo (CAPS-SSA) [Onasch et al., 2015], characterize extinction and scattering of the same volume of air, thus alleviating some of this concern and making the difference method a viable one for absorption measurement. However, scattering measurements require "truncation" correction to account for the small-angle scattering from larger particles that cannot be detected due to overlap with the incident light beam, and thus concerns over accuracy for absorption measurement remain, especially when the SSA is close to unity. The CAPS-SSA, which has seen limited deployment on aircraft, may provide a means towards in situ measurement of vertical profiles of absorption.

Unlike $\mathrm{BC}$ and dust, $\mathrm{BrC}$ (which is not a unique substance) may be soluble, at least to some extent, in water and other solvents such as methanol. As such, its spectrally varying absorption properties can be characterized by either collecting particles on filters and then performing solvent extraction or by direct dissolution into a solvent for online analysis [Zhang et al., 2011]. Such solvent-based methods provide a means to characterize the absorption properties of $\mathrm{BrC}$ separately from BC and dust, and samples can be collected from aircraft platforms [Liu et al., 2015]. However, it is not established whether the dissolution process influences the $\mathrm{BrC}$ absorptivity, and the total absorptivity and spectral variation depend on the solvent used [Zhang et al., 2013]. Further efforts to quantitatively understand the relationship between measurements of solvent-extracted absorption and suspended-particle absorption may help in apportionment of $\mathrm{BrC}$ absorption.

Apportionment of Absorption: The total absorption is the sum of the absorptions of all contributing components ( $\mathrm{BC}, \mathrm{BrC}$ and dust), and the climate impacts will depend on the integration of these contributions over the entire solar spectrum. Quantifying the contributions from each AA type is important to attribute impacts to sources, and to understand how these might change in the future due to changes in emission sources resulting from technological advances or in response to climate change. Efforts to allow for quantitative sampling and measurement of AA as a function of particle size would facilitate improved apportionment of in situ absorption. For example, such efforts can likely separate dust from BC and BrC, since dust contributions are typically from larger particles. However, quantitative characterization of particles with diameters greater than one micrometer is challenging because of inertial losses during sampling, especially on aircraft, and can be further exacerbated by losses within instruments that are not designed to maximize transmission of such particles. Other techniques to apportion $\mathrm{BC}$ and $\mathrm{BrC}$ absorption are making use of the differences in the wavelength dependence of absorption of these two types, and heating of the suspended particles to drive off the presumably more volatile $\mathrm{BrC}$ (i.e., denuding). It was concluded that future studies with concurrent use of multiple methodologies would facilitate improved apportionment of $\mathrm{BrC}$ and BC absorption.

Influence of Water on Particle Absorption: Most measurements of particulate light absorption have been made under dry conditions. However, the effects of particulate water on light absorption by AA particles, both within and outside of clouds, can substantially alter the climate impacts of AA [Jacobson, 2001; 2014], as water, like other non-absorbing particulate components, can serve as a coating on $\mathrm{BC}$ or dust, and can dissolve $\mathrm{BrC}$, each of which leads 
to an increase in the calculated per-particle absorptivity [Redemann et al., 2001] (Figure 3). Despite the importance of water uptake on absorption, experimental studies on this topic are extremely limited. One study on water uptake on BC particles concluded that this process led to a substantial increase in absorption, but the uncertainty on these measurements was sufficiently large as to render the results inconclusive [Mikhailov et al., 2006]. Another study, using a somewhat water-soluble BrC surrogate (nigrosin), found that absorption increased continuously as $\mathrm{RH}$ increased, by about $30 \%$ from dry to $95 \% \mathrm{RH}$ [Brem et al., 2011]. They also found that absorption for BrC-containing (and BC-free) particles generated from wood pyrolysis increased notably only when the $\mathrm{RH}$ was greater than $90 \%$, albeit with relatively large measurement uncertainties. A key experimental challenge to the characterization of the influence of water on absorption has been the ability to accurately measure absorption under high RH conditions.

Direct absorption measurement techniques are typically not well-suited to such measurements. The difference method was identified as the most promising avenue towards quantification, both in the laboratory and ultimately in the field, although this approach is not without difficulties (i.e., taking the difference of two larger numbers that increasingly approach each other at higher $\mathrm{RH}$ values). The ability of new instrumentation to measure extinction and scattering on the same volume of air alleviates many of the concerns regarding differences in $\mathrm{RH}$ between instruments, but the influences of changes in particle size resulting from water uptake will still require careful attention to detail. Instrument development and testing coupled with laboratory process-oriented experiments will serve as reference understanding for ultimate field deployment, both at surface sites and on aircraft platforms. Such RH-dependent measurements are critical, both to ultimately understand and validate results from remote sensing methods, which characterize particle absorption in the ambient environment, and to quantify the radiative forcing of $A A$ in real-world conditions.

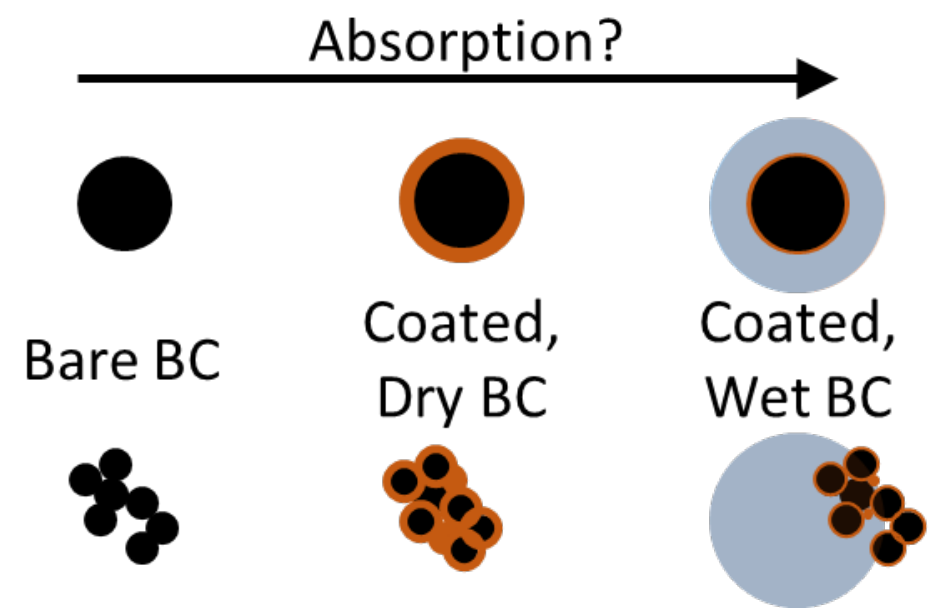

Figure 3. Experimental understanding of the influence of water uptake on absorption by AA, including BC as illustrated here, remains limited.

AA Quantification and Chemical Characterization: Global models typically simulate mass concentrations and size distributions, which are then used to calculate light absorption. Therefore, quantification of the abundance of atmospheric AA, in addition to absorption 
measurements, is necessary so that relationships between amount and absorption can be established and variability in these relationships can be understood.

Non-optical quantification of BC abundance is typically performed using one of a few available methods. So-called "elemental carbon" (EC) concentrations are determined by collection of particles on filters followed by conversion to $\mathrm{CO}_{2}$ and detection. It is typically assumed that EC and BC are equivalent, which may not be correct, and the EC method is not well-suited for aircraft measurements, although filter samples collected in situ (including on UASs) can in principle be returned to the lab for analysis. Uncertainties and biases in the EC method are only reasonably well established. The concentration of so-called "refractory BC" $(\mathrm{rBC})$ is determined by optically heating particles in situ through absorption of laser light and measuring their subsequent incandescence, the assumption being made that the intensity of this incandesced light is directly proportional to the mass of $r B C$. The commercial Single Particle Soot Photometer (SP2) characterizes the mass of $\mathrm{rBC}$ in individual particles by this method, from which mass concentrations and size distributions of rBC in ambient aerosol can be determined. The SP2 is suitable for use on mobile (i.e. aircraft) platforms. Advanced analysis of SP2 data can provide some information on the relative amount of non-rBC material in a given particle, although interpretation of this information has proven challenging [Sedlacek et al., 2012; Sedlacek et al., 2015]. The recently-developed commercial Soot Photometer Aerosol Mass Spectrometer (SP-AMS) also characterizes rBC by optical heating, but measures the carbon molecules that evaporate as the $\mathrm{rBC}$-containing particles reach their sublimation temperature [Onasch et al., 2012]. The quantitative capability of the SP-AMS is an active area of investigation. The SP-AMS can be deployed on aircraft, although it is currently better suited for in-plume measurements than for background-level measurements. The SP-AMS also characterizes other chemical components in the rBC-containing particles, and thus can provide additional information about the chemical nature and evolution of $\mathrm{rBC}$ in the atmosphere. Overall, greater effort to understand the comparability of the $B C$ measured by these different methods is needed, as is understanding of the limitations and biases of these methods in different environments.

Quantification of $\mathrm{BrC}$ is challenged by the fact that $\mathrm{BrC}$ is not a unique substance, but rather any organic aerosol substance (other than BC) that absorbs light. Understanding the chemical nature of $\mathrm{BrC}$ is needed to establish the extent to which $\mathrm{BrC}$ characteristics and emissions differ between sources (e.g. open burning versus residential wood combustion) and how the light absorption properties of $\mathrm{BrC}$ evolve through atmospheric processing, either through formation of $\mathrm{BrC}$ or degradation. It is clear that different components of OA have different inherent absorptivities, but we currently have limited understanding what chemical factors drive this variability and what is characterized as "BrC". A current question is the number of classes of $\mathrm{BrC}$ necessary to accurately characterize and parameterize its optical properties. New methods and approaches, both phenomenological and molecular, are needed.

Characterization and quantification of mineral dust and its absorption is limited by a lack of quantitative, in situ methods for determination of both abundance and chemical composition. The use of single particle aerosol mass spectrometers can provide some perspective on abundances and chemical characteristics of mineral dust within a complex mixture of particles, but these instruments are substantially limited by their semi-quantitative nature. As diameters of 
mineral dust particles are often greater than one micrometer, particle size can be used to estimate dust concentrations in areas where dust dominates aerosol mass in that size range. However, such an estimate would not include the contribution from smaller dust particles and thus would underestimate the total absorption from dust. Particles can be collected on filters and analyzed using offline methods, as is done by the IMPROVE network, for example. However, such an approach is not suited for aircraft measurements of absorption.

The workshop identified improvements and new developments in in situ measurement of aerosol absorption and of absorbing mass concentrations that are needed to help address scientific gaps in the radiative impacts of absorbing aerosol:

1. Adequacy of long-term records. Determining the extent to which long-term records of particulate light absorption made using filter-based methods are subject to biases.

2. Instrument development and validation. Development of robust, non-filter-based methods for long-term monitoring and aircraft-deployable in situ absorption measurements, and extension of the range of wavelengths used. Quantitative understanding of the comparability of different BC measurement techniques, including their limitations and biases in different environments

3. Attribution. Improvement in the attribution of absorption among the different AA types.

4. Water-uptake effects. Determining the extent to which water uptake impacts absorption by AA and how such effects depend on particle composition.

5. BC-containing particle characterization. Identification of $\mathrm{BC}$-containing particle shape and morphology (i.e., location of various components within the particle) and examination of their effects on the particle optical properties.

6. Brown carbon composition. Identification of which chemical components of the total organic aerosol contribute most to the $\mathrm{BrC}$ burden, and how these are altered by chemical processing.

\subsubsection{Remote Sensing of Absorbing Aerosols}

Both passive sun photometry retrievals and active lidar retrievals infer aerosol absorption from the difference between remotely sensed quantities characterizing extinction and scattering. In the case of sun photometry, the "extinction" is the column-integrated, line-of-sight extinction (equal to the AOD divided by the cosine of the solar zenith angle) and the "scattering" is the diffuse sky radiance. For active lidar retrievals, the "extinction" is the distance-resolved particulate extinction coefficient and the "scattering" is the particulate backscatter coefficient. Qualitatively, both of these retrieval approaches yield information on aerosol size distribution primarily from the magnitude and wavelength dependence of the observed extinction. The angularly-resolved scattering (in the case of the AERONET and SKYNET retrievals), or the hemispheric diffuse flux (in the case of the ARM MFRSR retrievals), or the wavelengthdependent 180-degree backscatter (in the case of the 3b-2a lidar), permits inference of the real and imaginary parts of the refractive index, and thus of the various bulk optical properties via a radiative transfer code. The size distribution together with the complex index of refraction (and to an extent the particle shape or "sphericity") then dictate the angular distribution of scattered light. Ultimately, average, effective values of the real and imaginary refractive index of the particles, which characterize their absorptivity, are retrieved through numerical inversion. In the 
case of AERONET, the refractive index is assumed size-independent, which limits the ability to separately retrieve AAOD values for "fine" and "coarse" mode particles and therefore the apportionment of absorption among the different components. "Fine" and "coarse" correspond qualitatively to smaller and bigger particles, respectively; in terms of absorption, these size ranges can be approximately interpreted as $\mathrm{BC}$ - and $\mathrm{BrC}$-dominated (fine) and dust-dominated (coarse).

There are several different sets of radiative transfer code underpinning the AA retrievals from various observation networks (AERONET, SKYNET, ARM MFRSR-CIP, OMI, AIR-MISR), and it is conceivable that differences in these radiative transfer code packages might generate disagreement between retrievals from these different sources. However, while differences do exist between AA retrievals from these networks, controlled sensitivity studies suggest that their magnitudes are greater than model differences can explain, and instead indicate differences in instrument calibration as the primary source of retrieval differences, with differences in assumed surface albedo as the second source.

The workshop identified improvements and new developments in remote sensing retrievals of aerosol absorption that would address scientific gaps in the radiative impacts of absorbing aerosol:

1. Validation. Improved validation of remote sensing of absorbing aerosol optical depth measurements through targeted field studies

2. AA vertical profiles. Extension of remote sensing methods to allow for retrieval of vertical profiles of $A A$.

3. Instrument calibration. Improvements in calibration methods associated with surfacebased remote sensing methods.

\subsubsection{AA Modeling Needs}

Determining the climate impacts of AA from regional and global models requires accurate representation of the atmospheric aerosol and its lifecycle as a whole, including the spatial distribution of AA concentrations and the AA absorptivity. This section illustrates the challenges that regional and global models face in this regard. The macroscale impacts of AA (e.g. on heating rates) are ultimately determined by particle-scale processes. Thus, the task of aerosol modeling is a prime example of a multiscale problem, with two distinct aspects: (i) representation of the aerosol population itself (size distribution, composition, particle shape) and its optical properties, and (ii) spatial resolution and the representation of sub-grid processes in a model with coarse grid spacing. An important issue is that the aerosol representation in global models must adequately represent the impacts of both AA and cloud condensation nuclei (CCN) and ice nuclei (IN) activity to account for the various competing direct and indirect effects.

Aerosol aging and the evolution of aerosol mixing state and morphology. Field campaigns show a large variation in composition and morphology of individual particles [China et al., 2013] that reflects diversity in particle sources and in atmospheric processing. Aerosol populations evolve dynamically in the atmosphere as a result of "aging" processes such as formation of 
secondary aerosol and photochemical processes. Individual aerosol particles rarely consist of a single species but rather of mixtures of species, meaning that an individual aerosol particle can contain black carbon and other species such as sulfate, mineral dust, or brown carbon [Adachi and Buseck, 2008]. Adding complexity, these constituents can be arranged within the particle in different ways, resulting in different internal morphologies that can also evolve. Importantly, these details can be important for the particles' optical properties and the overall aerosol radiative impact, and they can also affect the aerosol radiative impact indirectly by modifying the lifetimes of absorbing aerosol particles; accumulation of hygroscopic material makes a particle more prone to removal from the atmosphere through cloud processes.

Spatial resolution and sub-grid processes. Even if the model representation of aerosol aging were perfect, the problem of representing the aging processes in a model with coarse spatial resolution remains. The reason for this is that most processes that contribute to aerosol aging, such as coagulation or the chemical production of secondary aerosol, are non-linear in concentration. Depending on the spatial heterogeneity of the aerosol and gas phase emissions and on the complexity of the terrain and wind flow, the grid resolution can have an appreciable impact on the magnitude of the simulated radiative forcing. For example, [Gustafson et al., 2011] compared WRF-Chem simulations at two different model resolutions, $75 \mathrm{~km}$ and $3 \mathrm{~km}$, and determined an average daytime mean difference of over $30 \%$ in top-of-atmosphere shortwave ARI radiative forcing for a large percentage of central Mexico.

Key activities identified during the workshop that would help improve understanding of the processes that drive temporal and spatial variability in AA and in AA properties are:

1. Process-level model development and developing upscaling methods for physicsbased parameterization on the regional and global scale: Development of an integrated multi-scale model hierarchy that connects microscale models with meso- and macro-scale models in rigorous, quantitative ways would improve understanding of how to compare models on different scales and how to use fine-scale models with rigorous upscaling techniques.

2. Integrated laboratory and process modeling studies targeting AA evolution: Chamber studies that are conducted in close collaboration with process-level model development efforts would improve fundamental understanding of the relevant physical and chemical processes that underlie the evolution of AA in the atmosphere.

3. Laboratory and field studies to constrain model inputs: Laboratory and field studies that collect information on near-source AA properties such as size distribution and chemical composition would be useful to constrain model inputs. Measurements on the source-specific, wavelength-dependent refractive indices of the different chemical species, in particular those that comprise "BrC," are also required.

\subsubsection{Biomass Burning Lifecycle}

$\mathrm{BC}$ and $\mathrm{BrC}$ are formed during combustion of fossil fuels, biofuels, and biomass. Globally, current production of BC from these sources is split roughly $40 \% / 20 \% / 40 \%$, respectively [Bond 
et al., 2013], whereas that of $\mathrm{BrC}$ is not well established. Biomass combustion encompasses controlled burns, such as burning of crop stubble, and uncontrolled burns, i.e., wildfires, the frequency and intensity of which may change in response to climate change. The amount and properties of the $\mathrm{BC}$ and $\mathrm{BrC}$ produced in biomass combustion depends on a variety of factors, primary among which are burn conditions, fuel source, and other factors such as moisture content.

Biomass burning conditions are often classified as "flaming" (or "active burning") or "smoldering." More BC is produced under flaming conditions, whereas under smoldering conditions more organic aerosol (OA), which can include $\mathrm{BrC}$, is produced. The relative abundance of $\mathrm{OA}$ and $\mathrm{BC}$ largely determines the relative amounts of scattering and absorption. Biomass burning also produces other substances such as non-absorbing inorganic substances and gaseous organic compounds that can react within plumes to form SOA.

Emissions from biomass burn (BB) events are large yet poorly quantified [De Gouw and Jimenez, 2009]. Bottom-up (inventory-based) and top-down (remote-sensing observationbased) estimates of global BB emissions differ substantially, potentially due to inaccuracies in BB emission factors, poor representation of BB aerosol processes in models, and/or errors in BB aerosol optical properties [Kaiser et al., 2012]. Biomass burn events are highly sporadic in time and space, with large interannual variability and regional differences in their atmospheric impacts [Park et al., 2007]. The impacts of BB emissions will be exacerbated under a changing climate, which is likely to increase not only the frequency of these events, but also their magnitudes [Dennison et al., 2014]. Moreover, the injection height of BB emissions depends on the burn and meteorological conditions, leading to a corresponding range of impacts depending on whether the absorbing aerosol ends up below, above, or within clouds. For all of these reasons, accurate modeling of biomass burning events and their effects over a range of temporal (daily to seasonally) and spatial (regional to global) scales is extremely challenging.

Even though biomass burning is a dominant source of $\mathrm{BC}$ and $\mathrm{BrC}$, its net effect on Earth's radiation budget is not well understood, and the sign of the forcing is not constrained. $\mathrm{BC}$ and $\mathrm{BrC}$ exert positive forcings (i.e., warming) through direct absorption of solar radiation and semidirect effects such as more rapid evaporation of clouds. However, co-emitted substances can modify the hygroscopic and optical properties of $\mathrm{BC}$ and $\mathrm{BrC}$ aerosol particles, which can lead to either a reinforcement of the positive forcing through enhanced absorption, or to a negative forcing though increased light scattering and cloud formation. The IPCC AR5 concluded that BB aerosols are net climate neutral $(0.0 \pm 0.2) \mathrm{W} \mathrm{m}^{-2}$ [IPCC, 2013], whereas [Bond et al., 2013] estimated total climate forcing by biomass burning to be slightly negative $\left(\sim-0.15 \mathrm{~W} \mathrm{~m}^{-2}\right)$ with an uncertainty that included the possibility of positive forcing (Figure 4). Determining the magnitude (and sign) of the forcing and reducing the uncertainty will require more detailed process-level understanding of these events. 


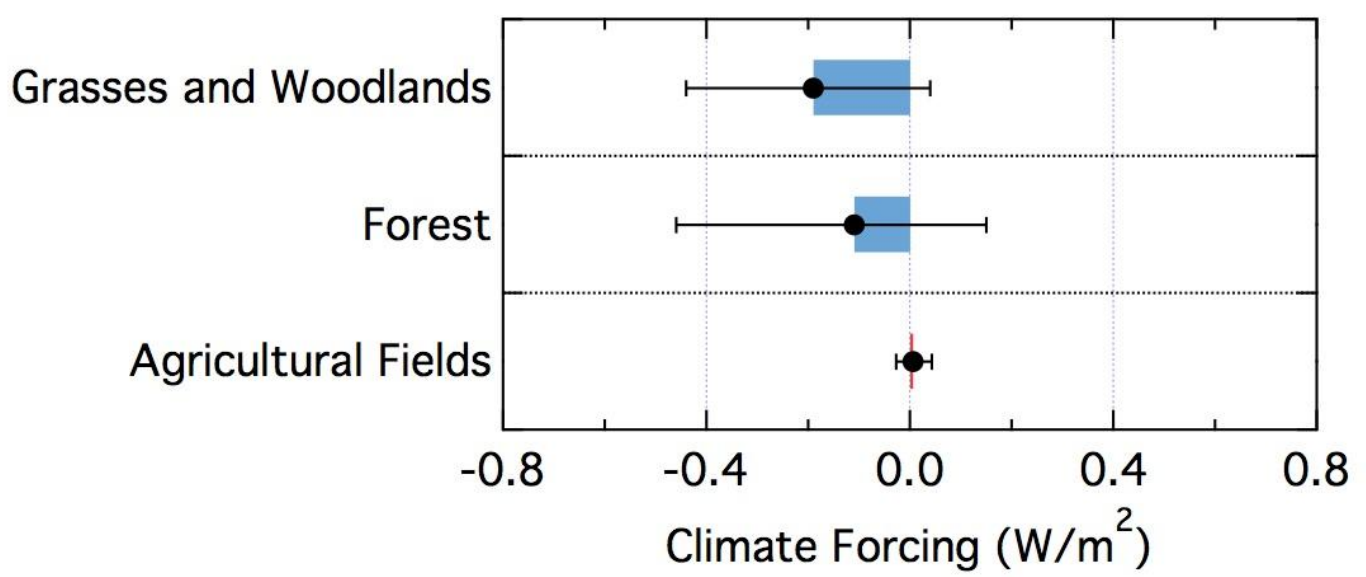

Figure 4. Total climate forcing for three biomass fuel sources continuously emitting at year2000 rates scaled to match observations in 2005 . The forcing estimate includes contributions from $\mathrm{ARI}$ and $\mathrm{ACl}$ from both absorbing and non-absorbing aerosol components. Black circle is best estimate; bars denote 1-s uncertainty. Colored regions drawn from zero to best estimate show sign of the forcing: blue regions denote negative forcing (cooling), whereas red region denotes positive forcing (warming). Adapted from Figure 37 in Bond et al., 2013.

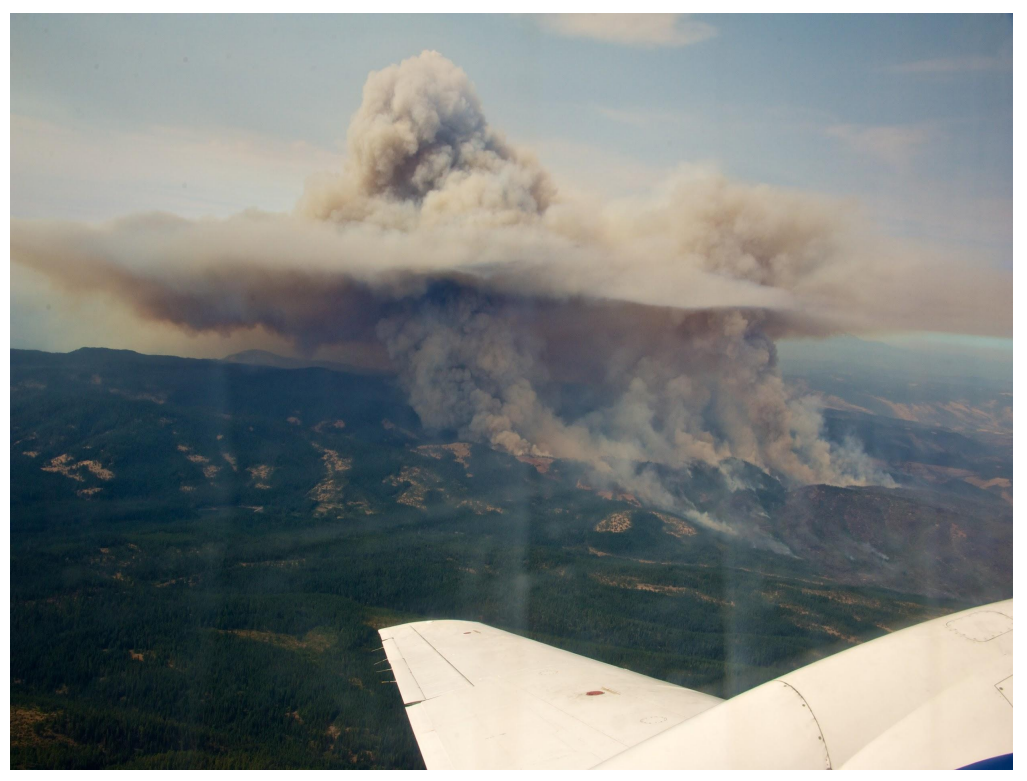

Figure 5. Photograph of the Government Flats Complex fire sampled during BBOP on August 21, 2013.

Improved understanding of the transformation ("aging") processes that AA undergo in biomass burning plumes was identified at the workshop as an important need. Both the 
hygroscopic and optical properties of particles within BB plumes evolve with time. BC particles are hydrophobic when formed, but their hygroscopicity, which affects their ability to form cloud drops, evolves as the plume dilutes and cools, enabling the condensation of other co-emitted species on these particles. Similarly, condensation controls the evolution of the compositional and morphological mixing states of BC particles, which determine their optical properties and thus their ability to scatter and absorb light. However, the time scales for the evolution of the hygroscopic and optical properties are not well constrained and can differ from one BB event to another. Determination of the evolving hygroscopic and optical properties of BC and their respective rates of evolution thus remain essential to reducing uncertainty of BB effects on climate. It was concluded that these topics can be addressed through process-oriented, targeted laboratory and field studies.

$\mathrm{BrC}$ particles from BB events have several formation mechanisms: they can be a component of the primary organic aerosol (POA) particles emitted directly from the burn, they can be formed when initially non-absorbing POA particles undergo chemical reactions that modify their light-absorption properties, and they can be produced downwind of a BB event as SOA when co-emitted gaseous species condense on existing particles. Finally, tar balls, a specific type of $\mathrm{BrC}$ particles found only in some wildfires, likely result from yet another formation pathway [Hand et al., 2005; Pósfai et al., 2004]. This range of formation mechanisms is expected to lead to $\mathrm{BrC}$ having a range of optical properties, depending on the characteristics of the fire, fuel source, and environmental conditions. These properties and their spectral dependences may evolve with time through physical processes (condensation or evaporation, as well as coagulation) and through chemical processes (reactions within the particle). Additionally, photochemical "bleaching" due to solar radiation can affect the optical properties of $\mathrm{BrC}$, reducing its light-absorption.

Despite being composed of countless different compounds with a wide range of formation mechanisms, $\mathrm{BrC}$ is typically considered as a unique substance with a single set of optical properties. However, observations show that what is referred to as $\mathrm{BrC}$ actually encompasses a range of spectral dependencies [Lewis et al., 2008]. An open question is how best to describe this range of variability. For instance, how many subcategories of $\mathrm{BrC}$ are required to accurately capture the variability of optical properties and their spectral dependences? Once this has been established, the evolution of the spectral dependences of the optical properties of various $\mathrm{BrC}$ subclasses can be examined.

Key research activities identified during the workshop that can help address scientific gaps and reduce the uncertainty in the radiative impacts of absorbing aerosol from BB events on Earth's climate are:

(1) Attribution of $\mathrm{BC}$ and $\mathrm{BrC}$ absorption. Improved measurement of light absorption by AA in the UV is necessary to facilitate both attribution of $B C$ and $\mathrm{BrC}$ absorption and development of a robust classification scheme of spectral dependencies of optical properties. Additionally, greater consideration of IR absorption will help separate dust from $\mathrm{BC}$ and $\mathrm{BrC}$.

(2) BB Aerosol Evolution. Focused laboratory studies and field campaigns aimed at developing a detailed, process-level understanding of BB aerosol evolution (especially absorption), and how this evolution depends on the mix of combustion processes that 
formed the aerosol, fuel source, actinic flux (i.e. day/night differences), and other factors, is necessary to obtain data required for model inputs.

(3) Measurement Needs. Instrument development and targeted laboratory studies to comprehensively map the instrumental performance envelope towards BB-centric aerosols (e.g., tar balls) are required to attribute BB absorbing aerosols to sources, to study their evolution, to quantify their radiative impacts, and to accurately represent BB absorbing aerosol properties and processes in models. Additionally (as noted above), development of techniques that can measure $A A$ at ambient $\mathrm{RH}$ is required.

(4) Vertical Distribution of BB aerosol and absorption. Characterization of the vertical distribution of BB aerosol and aerosol absorption can best be done through 1) increased in situ vertical profile measurements of absorbing aerosol abundances and properties using both manned aircraft (e.g., G-1) and UASs, and 2) improving retrievals from existing surface-based ARM measurements by combining multi-wavelength optical data with aerosol size distributions and composition data.

\subsubsection{AA-Cloud-Surface Interactions}

Absorbing aerosols change the heating rates in the atmosphere, affecting the atmospheric stability and thus vertical transport of water, and thus modifying the cloud and thermodynamic structure of the atmosphere. A number of feedbacks between clouds and absorbing aerosols have been discussed: (1) interactions of aerosols, including absorbing aerosols, with atmospheric dynamics, especially for boundary layer clouds and likely for deep convection [e.g. Rosenfeld et al., 2008; Stevens and Feingold, 2009] (2) effects of the chemical and physical properties of aerosols that are entrained into a cloud system on cloud optical properties, thermodynamics and lifecycle [Koren et al., 2008; Shrivastava et al., 2013; Wood, 2012], and (3) land, ocean, and biosphere responses to aerosol forcing and consequently the formation of clouds [e.g. Menon et al., 2002; Ramanathan et al., 2005; Shindell et al., 2012]. In addition, feedbacks between AA and surface can affect Earth's radiative balance through deposition on high albedo surfaces [Flanner, 2013; Hansen and Nazarenko, 2004].

Although the aerosol concentration typically decreases rapidly from the top of the boundary layer to the mid troposphere, layering of the aerosols just above the boundary layer $(2-3 \mathrm{~km})$ and mid troposphere $(5-7 \mathrm{~km})$ has been frequently observed in many locations. When AA are present above (Figure 6a) or below the cloud layer (Figure 6b), they stabilize the boundary layer by heating the layer in which they are contained and cooling the layer below, leading to suppressed moisture and heat fluxes from the surface and hence suppressed cloud formation inside or below the aerosol layer. If enhanced absorption due to the presence of these aerosols inside the cloud elements results in radiative heating, evaporation of cloud drops might lead to shrinking of the cloud elements and possibly reduced cloud coverage (Figure 6c). Hence, the absorption characteristics of these aerosols generally tend to result in thermodynamic stabilization and reduction in cloud cover. However, absorbing aerosols can also affect cloud properties through indirect effects that lead to decreases in cloud drop sizes and increases in cloud cover. Additionally, it has been suggested that stratocumulus clouds thicken beneath layers of absorbing smoke aerosols. Hence, AA exhibit multiple competing effects on cloud and 
thermodynamic structure (semi-direct versus Indirect), and the extent of their impact is still a matter of debate.
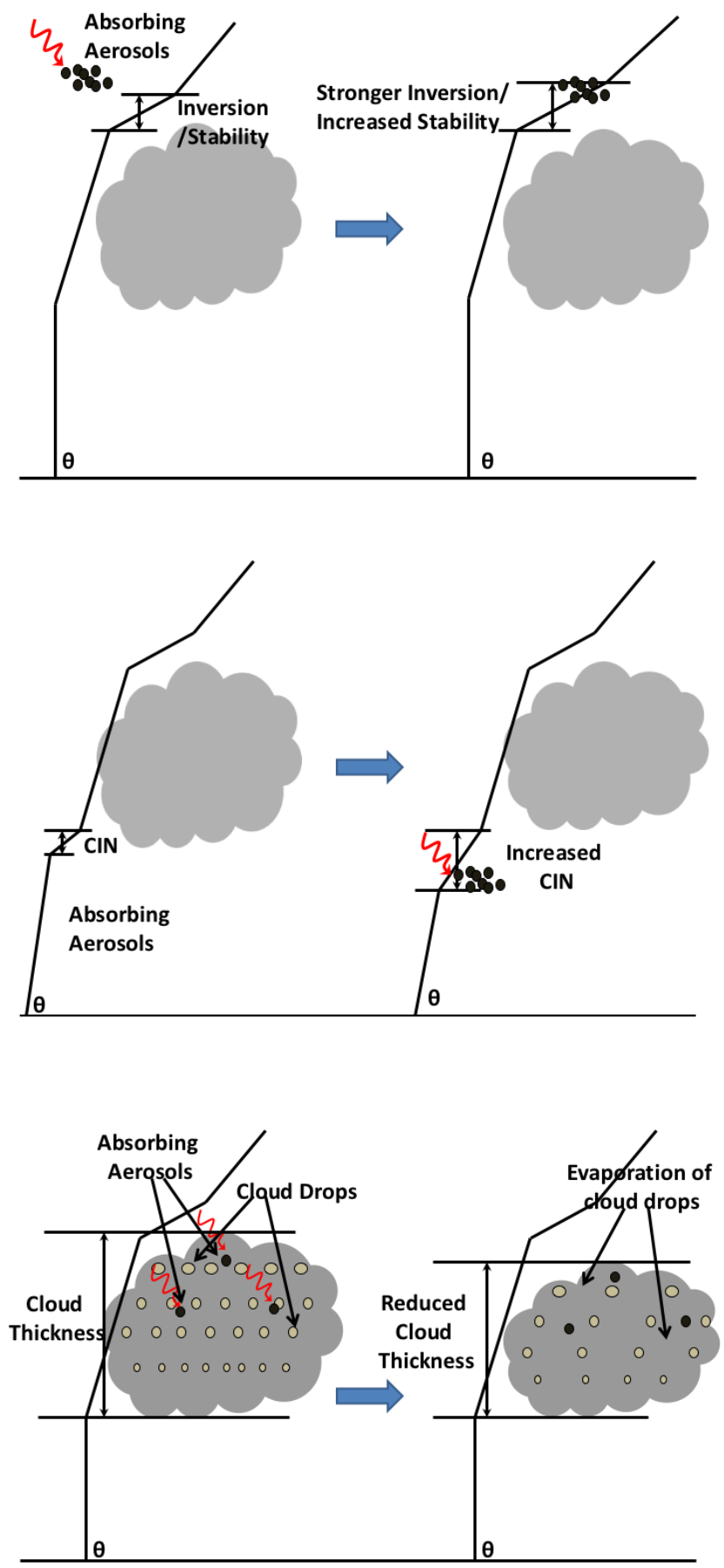

Figure 6. Hypothesized impact of absorbing aerosols on (a) boundary layer inversion, (b) convective inhibition, and (c) cloud size and drops. CIN, Convective Inhibition, is a quantitative measure of the inhibition of convective activity; lower CIN implies lower stability. 
One of the major issues confronting aerosol climate simulations of the Arctic and Antarctic Cryospheres is the lack of detailed data on the vertical and spatial distribution of aerosols with which to test these models. This is due, in part, to the inherent difficulty of conducting such measurements in extreme environments. However, given the pronounced sensitivity of the Polar Regions to radiative balance perturbations, it is incumbent upon our community to better understand and quantify these perturbations, and their unique feedbacks, so that robust model predictions of this region can be realized. With respect to $A A$, the cryosphere is a truly unique region in that it provides these aerosols types two radiative forcing routes: atmospheric and nonatmospheric. In the atmospheric route light absorbing aerosols are expected to exert their radiative forcing impact much as they do in the mid-latitudes - through mid-altitude warming (direct effect) and alteration of cloud lifetime (semi-direct effect) collectively causing surface dimming and subsequent surface cooling [Flanner, 2013]. In addition, deposition of AA on the surface decreases the albedo, increasing surface light absorption, thus leading to more snow melt [Hansen and Nazarenko, 2004].

The workshop identified effects of absorbing aerosols on shallow clouds as a key area of further research. Primary challenges are:

1. High-resolution measurements. Measurement of aerosols chemical and physical properties on very short time scales and at very high spatial resolutions is necessary to address the fast atmospheric response to absorbing aerosol perturbations.

2. Measurements of AA vertical distribution. Measurements of the vertical distribution of AA amounts and their speciation together with co-located measurements of atmospheric state and radiative balance are required to investigate the interactions of $A A$ and clouds.

3. Model Development. Development of models with the necessary spatial resolution to accurately represent the interactions among meteorology, radiative transfer, aerosols and cloud formation is necessary. Overall, developing the theoretical and conceptual framework for separating the fast atmospheric response to aerosol perturbation from other known aerosol radiative feedbacks to meteorology is necessary for understanding the importance of these feedbacks in climate projections of the past and future.

4. Effects on Surface Albedo. Increased concurrent in situ measurements of surface albedo and absorbing aerosol abundance, especially over bright surfaces (e.g. snow and ice), is required to quantify the effects of AA deposition on surface albedo.

\section{Summary}

The ASR-sponsored workshop on absorbing aerosol brought together modeling and observational experts from within and outside of DOE to identify knowledge gaps and pinpoint research themes that can leverage the unique modeling and measurement capabilities available within the ASR and ARM programs to further our understanding of the climatological impacts of absorbing aerosols. This workshop reaffirmed the importance of and continuing need for improved measurement capabilities and expanded laboratory studies and field campaigns. These efforts can serve to further inform models and allow development of improved 
representations of absorbing aerosol processes and properties in models. Specifically, this workshop identified five topical areas that the ASR program is well positioned to address:

(i) characterization of the direct radiative forcing by $A A$ and attribution of forcing to aerosol type (e.g., BC, BrC, dust);

(ii) improvement of measurement and retrieval of $A A$;

(iii) representation of $A A$ properties and processes within models;

(iv) properties and evolution of $A A$ from biomass burning; and

(v) the impacts of AA on atmospheric dynamics, thermodynamics, and circulation; cloud formation and lifecycle; and the hydrological cycle.

The science questions behind each of these topical areas, along with key research activities that will address these science questions discussed in the sections above, are synthesized into science themes in Table 1. It was further recognized that success in any of these science themes is predicated on strong communication between the modeling and observational/experimental communities in both the design and the execution of field campaigns and targeted laboratory studies. Finally, the synergy between the ARM measurement and the ASR science programs was recognized as a unique and powerful combination of complementary capabilities that will ensure that DOE will continue to actively contribute to the area of absorbing aerosol climate science and remain a leader in this area 


\section{Table 1: Science Themes, Questions, and Key Research Activities.}

\section{Science Theme 1: Direct Radiative Forcing from AA}

\begin{tabular}{|l|l|}
\hline \multicolumn{1}{|c|}{ Science Questions } & \multicolumn{1}{c|}{ Key Research Activities } \\
\hline - What are the absolute and relative & - Assess the performance of current remote-sensing \\
contributions at a given time/location of & AAOD retrievals through a targeted field study. \\
various absorbing types (black carbon, & - Develop methodologies and techniques for the \\
brown carbon, and dust)? & apportionment of the contributions of the different AA \\
- How do these contributions depend on & types (BC, BrC, and dust) to AAOD retrievals. \\
atmospheric conditions? & - Develop next-generation AAOD retrieval methods having \\
- How can these contributions be attributed & lower detection thresholds and improved vertical \\
to source (e.g., natural vs. & resolution. \\
anthropogenic)? & - Examine the extent to which surface in situ \\
How might these contributions change in & measurements of AA are representative of the entire \\
a changing climate? & column, and how such relationships vary in time and \\
To what extent are point, especially & space. \\
surface, measurements representative of & - Develop methodologies to determine the factors that \\
column values? & govern the vertical distribution of AA on local and \\
What factors govern the vertical & regional scales. \\
distribution of AA on local and regional & Improve calibration methods associated with surface- \\
scales? & based remote sensing methods. \\
\hline
\end{tabular}

\section{Science Theme 2: AA Measurement Needs}

\begin{tabular}{|l|l|}
\hline \multicolumn{1}{|c|}{ Science Questions } & \multicolumn{1}{c|}{ Key Research Activities } \\
\hline - How do AA properties depend upon & - Determine the extent to which long-term records of \\
ambient conditions (especially RH)? & absorption made using filter-based methods are subject \\
- How does absorption of various AA types & to biases. \\
depend on wavelength? & - Develop robust, non-filter-based methods for in situ \\
- What is the compositional/morphological & absorption measurements. \\
$\begin{array}{l}\text { (i.e., mixing state) dependence of } \\
\text { absorption? }\end{array}$ & $\begin{array}{l}\text { Quantify limitations and biases of different AA } \\
\text { - What are the contributions to }\end{array}$ \\
$\begin{array}{l}\text { model/measurement discrepancies in } \\
\text { AAOD attribution (BC vs. BrC vs. dust), } \\
\text { and BC inventories versus those that are } \\
\text { intrinsic to the models (e.g., transport, }\end{array}$ & - Improve attribution of absorption among different AA \\
aging timescales, relating concentration to & - Determine the extent to which absorption is influenced \\
absorption)? & by water uptake and how this depends on particle \\
Can these discrepancies be reduced with & composition. \\
current in situ techniques? & Determine the dependence of optical properties of BC- \\
& containing particles on shape and morphology. \\
& Identify which chemical components of the total organic \\
& aerosol contribute most to the BrC burden. \\
& Extend remote sensing methods to allow for retrieval of \\
& vertical profiles of AA. \\
\hline
\end{tabular}


Science Theme 3: AA Modeling Needs

\begin{tabular}{|l|l|}
\hline \multicolumn{1}{|c|}{ Science Questions } & \multicolumn{1}{c|}{ Key Research Activities } \\
\hline - What are the spatial and temporal scales & - Develop an integrated multi-scale model hierarchy that \\
necessary to accurately capture AA & connects microscale models with meso- and macro- \\
processes? & scale models. \\
- What is the best way to represent AA size & - Conduct chamber studies in coordination with process- \\
distributions, optical and microphysical & level model development to improve understanding of \\
properties, and their evolution in models? & AA evolution. \\
- To what extent are model/measurement & - Conduct laboratory and field studies to constrain model \\
discrepancies due to model representation & inputs. \\
vs. measurement uncertainty? & - Measure source-specific, wavelength-dependent \\
- What factors govern the vertical distribution & refractive indices of various BrC substances. \\
of AA on a local and regional scale? & \\
\hline
\end{tabular}

\section{Science Theme 4: Biomass Burning Lifecycle}

\begin{tabular}{|l|l|}
\hline \multicolumn{1}{|c|}{ Science Questions } & \multicolumn{1}{c|}{ Key Research Activities } \\
\hline - What factors and processes control the net & - Extend range of wavelengths over which AA is \\
radiative effects of BB aerosols? & measured to improve attribution, especially of BrC. \\
- How do these factors and processes vary & - Conduct laboratory studies and field campaigns to \\
by region and across scales? & investigate the dependence of BB aerosol evolution on \\
- How might they behave in a changing & various factors such as combustion conditions, fuel \\
climate? & source, and actinic flux (i.e. day/night differences). \\
- What are the semi-direct impacts of BB & - Determine instrument detection and characterization \\
emissions on clouds lifetime? & capabilities of BB aerosols (e.g., for tar balls). \\
- What is the role of BB entrainment and & - Develop techniques to measure AA at ambient RH. \\
evaporation in clouds? & $\begin{array}{l}\text { Measure the vertical distribution of BB aerosols and AA } \\
\text { - What role does the diurnal cycle play in BB }\end{array}$ \\
aerosol processing and evolution? & - Improve retrievals from existing surface-based ARM \\
- What is the optimal classification of & measurements by combining multi-wavelength optical \\
absorbing aerosols (e.g., number of types & data with aerosol size distributions and composition \\
of brown carbon, tar balls, etc.)? & data. \\
\hline
\end{tabular}

Science Theme 5: AA-Cloud-Surface Interactions

\begin{tabular}{|l|l|}
\hline \multicolumn{1}{|c|}{ Science Questions } & \multicolumn{1}{c|}{ Key Research Activities } \\
\hline $\begin{array}{l}\text { - How do the spatial and temporal } \\
\text { distributions of AA impact atmospheric } \\
\text { thermodynamics and circulation? }\end{array}$ & $\begin{array}{l}\text { Conduct measurements of aerosol chemical and } \\
\text { physical properties on very short time scales and at very } \\
\text { high spatial resolutions. }\end{array}$ \\
- How might responses of atmospheric & - Measure the vertical distribution of AA and its speciation \\
thermodynamics and circulation to AA & together with co-located measurements of atmospheric \\
change in a changing climate? & state and radiative balance. \\
- How do the spatial and temporal & - Develop models with the necessary spatial resolution to \\
distributions of AA impact the water cycle & accurately represent the interactions among \\
regionally and globally? & meteorology, radiative transfer, aerosols, and cloud \\
What factors govern the vertical distribution & formation. \\
of AA on local and regional scales? & Conduct in situ measurements of surface albedo over \\
- What are the impacts of surface albedo & snow and ice with concurrent AA measurements. \\
change due to deposition of AA and how & \\
might this change in the changing climate? & \\
\hline
\end{tabular}




\section{References}

Adachi, K., and P. R. Buseck (2008), Internally mixed soot, sulfates, and organic matter in aerosol particles from Mexico City, Atmospheric Chemistry and Physics, 8(21), 6469-6481. Bond, T. C., et al. (2013), Bounding the role of black carbon in the climate system: A scientific assessment, Journal of Geophysical Research: Atmospheres, 118, 1-173, doi:10.1002/jgrd.50171.

Bond, T. C., D. G. Streets, K. F. Yarber, S. M. Nelson, J.-H. Woo, and Z. Klimont (2004), A technology-based global inventory of black and organic carbon emissions from combustion, $J$. Geophys. Res., 109(D14), D14203, doi:10.1029/2003jd003697.

Brem, B. T., F. C. Mena Gonzalez, S. R. Meyers, T. C. Bond, and M. J. Rood (2011), Laboratory-Measured Optical Properties of Inorganic and Organic Aerosols at Relative Humidities up to 95\%, Aerosol Science and Technology, 46(2), 178-190, doi:10.1080/02786826.2011.617794.

Cappa, C. D., D. A. Lack, J. B. Burkholder, and A. R. Ravishankara (2008), Bias in filter-based aerosol light absorption measurements due to organic aerosol loading: Evidence from laboratory measurements, Aerosol Science and Technology, 42(12), 1022-1032, doi:Doi 10.1080/02786820802389285.

Cappa, C. D., et al. (2012), Radiative absorption enhancements due to the mixing state of atmospheric black carbon Science, 337, 1078-1081, doi:10.1126/science.1223447. China, S., C. Mazzoleni, K. Gorkowski, A. C. Aiken, and M. K. Dubey (2013), Morphology and mixing state of individual freshly emitted wildfire carbonaceous particles, Nat Commun, 4 , doi:10.1038/ncomms3122.

Davidi, A., A. B. Kostinski, I. Koren, and Y. Lehahn (2012), Observational bounds on atmospheric heating by aerosol absorption: Radiative signature of transatlantic dust, Geophysical Research Letters, 39(4), n/a-n/a, doi:10.1029/2011GL050358.

De Gouw, J., and J. L. Jimenez (2009), Organic Aerosols in the Earth's Atmosphere, Environmental Science \& Technology, 43(20), 7614-7618, doi:10.1021/es9006004.

Dennison, P. E., S. C. Brewer, J. D. Arnold, and M. A. Moritz (2014), Large wildfire trends in the western United States, 1984-2011, Geophysical Research Letters, 41(8), 2928-2933, doi:10.1002/2014GL059576.

Feng, Y., V. Ramanathan, and V. R. Kotamarthi (2013), Brown carbon: a significant atmospheric absorber of solar radiation?, Atmos. Chem. Phys., 13(17), 8607-8621, doi:10.5194/acp-13-8607-2013.

Flanner, M. G. (2013), Arctic climate sensitivity to local black carbon, Journal of Geophysical Research: Atmospheres, 118(4), 1840-1851, doi:10.1002/jgrd.50176.

Gustafson, W. I., Y. Qian, and J. D. Fast (2011), Downscaling aerosols and the impact of neglected subgrid processes on direct aerosol radiative forcing for a representative global climate model grid spacing, Journal of Geophysical Research: Atmospheres, 116(D13), n/a-n/a, doi:10.1029/2010JD015480.

Hand, J. L., et al. (2005), Optical, physical, and chemical properties of tar balls observed during the Yosemite Aerosol Characterization Study, Journal of Geophysical Research: Atmospheres, 110(D21210), D21210, doi:10.1029/2004JD005728.

Hansen, J., and L. Nazarenko (2004), Soot climate forcing via snow and ice albedos, Proc. Natl. Acad. Sci. U. S. A., 101(2), 423-428, doi:10.1073/pnas.2237157100.

IPCC (2013), Climate Change 2013: The Physical Science Basis. Contribution of Working Group I to the Fifth Assessment Report of the Intergovernmental Panel on Climate Change, 1535 pp., Cambridge University Press, Cambridge, United Kingdom and New York, NY, USA. Jacobson, M. Z. (2001), Strong radiative heating due to the mixing state of black carbon in atmospheric aerosols, Nature, 409(6821), 695-697, doi:10.1038/35055518. 
Jacobson, M. Z. (2014), Effects of biomass burning on climate, accounting for heat and moisture fluxes, black and brown carbon, and cloud absorption effects, Journal of Geophysical Research-Atmospheres, 119(14), 8980-9002, doi:10.1002/2014jd021861.

Kaiser, J. C., J. Hendricks, M. Righi, N. Riemer, R. A. Zaveri, S. Metzger, and V. Aquila (2014), The MESSy aerosol submodel MADE3 (v2.0b): description and a box model test, Geosci. Model Dev., 7(3), 1137-1157, doi:10.5194/gmd-7-1137-2014.

Kaiser, J. W., et al. (2012), Biomass burning emissions estimated with a global fire assimilation system based on observed fire radiative power, Biogeosciences, 9(1), 527-554, doi:10.5194/bg9-527-2012.

Koren, I., J. V. Martins, L. A. Remer, and H. Afargan (2008), Smoke Invigoration Versus Inhibition of Clouds over the Amazon, Science, 321(5891), 946-949, doi:10.1126/science.1159185.

Lack, D. A., C. D. Cappa, D. S. Covert, T. Baynard, P. Massoli, B. Sierau, T. S. Bates, P. K. Quinn, E. R. Lovejoy, and A. R. Ravishankara (2008), Bias in filter-based aerosol light absorption measurements due to organic aerosol loading: Evidence from ambient measurements, Aerosol Science and Technology, 42(12), 1033-1041, doi:Doi 10.1080/02786820802389277.

Lewis, K., W. P. Arnott, H. Moosmüller, and C. E. Wold (2008), Strong spectral variation of biomass smoke light absorption and single scattering albedo observed with a novel dualwavelength photoacoustic instrument, Journal of Geophysical Research: Atmospheres, 113(D16), D16203, doi:10.1029/2007JD009699.

Liu, J., et al. (2015), Brown carbon aerosol in the North American continental troposphere: sources, abundance, and radiative forcing, Atmospheric Chemistry and Physics, 15(14), 78417858, doi:10.5194/acp-15-7841-2015.

Menon, S., J. Hansen, L. Nazarenko, and Y. F. Luo (2002), Climate effects of black carbon aerosols in China and India, Science, 297(5590), 2250-2253.

Mikhailov, E. F., S. S. Vlasenko, I. A. Podgorny, V. Ramanathan, and C. E. Corrigan (2006), Optical properties of soot-water drop agglomerates: An experimental study, Journal of Geophysical Research-Atmospheres, 111(D7), D07209, doi:10.1029/2005JD006389. Ogren, J. A., J. Wendell, P. J. Sheridan, D. Hageman, and A. Jefferson (2013), Continuous light absorption photometer performance, ASR Science Team Meeting, Potomac, Md, USA, 18-21 March, http://asr.science.energy.gov/meetings/stm/posters/view?id=781, Accessed: Onasch, T. B., P. Massoli, P. L. Kebabian, F. B. Hills, F. W. Bacon, and A. Freedman (2015), Single Scattering Albedo Monitor for Airborne Particulates, Aerosol Science and Technology, 49(4), 267-279, doi:10.1080/02786826.2015.1022248.

Onasch, T. B., A. M. Trimborn, E. C. Fortner, J. T. Jayne, G. L. Kok, L. R. WilliamS, P. Davidovits, and D. R. Worsnop (2012), Soot Particle Aerosol Mass Spectrometer: Development, Validation and Initial Application, Aerosol Science and Technology, 46(7), 804-817, doi:10.1080/02786826.2012.663948.

Park, R. J., D. J. Jacob, and J. A. Logan (2007), Fire and biofuel contributions to annual mean aerosol mass concentrations in the United States, Atmospheric Environment, 41(35), 73897400, doi:10.1016/j.atmosenv.2007.05.061.

Pósfai, M., A. Gelencsér, R. Simonics, K. Arató, J. Li, P. V. Hobbs, and P. R. Buseck (2004), Atmospheric tar balls: Particles from biomass and biofuel burning, Journal of Geophysical Research: Atmospheres, 109(D6), D06213, doi:10.1029/2003JD004169.

Ramanathan, V., C. Chung, D. Kim, T. Bettge, L. Buja, J. T. Kiehl, W. M. Washington, Q. Fu, D. R. Sikka, and M. Wild (2005), Atmospheric brown clouds: Impacts on South Asian climate and hydrological cycle, Proc. Natl. Acad. Sci. U. S. A., 102(15), 5326-5333, doi:10.1073/pnas.0500656102.

Redemann, J., P. B. Russell, and P. Hamill (2001), Dependence of aerosol light absorption and single-scattering albedo on ambient relative humidity for sulfate aerosols with black carbon 
cores, Journal of Geophysical Research: Atmospheres, 106(D21), 27485-27495, doi:10.1029/2001JD900231.

Rosenfeld, D., U. Lohmann, G. B. Raga, C. D. O'Dowd, M. Kulmala, S. Fuzzi, A. Reissell, and M. O. Andreae (2008), Flood or drought: How do aerosols affect precipitation?, Science, 321(5894), 1309-1313, doi:10.1126/science.1160606.

Sedlacek, A. J., E. R. Lewis, L. Kleinman, J. Xu, and Q. Zhang (2012), Determination of and evidence for non-core-shell structure of particles containing black carbon using the SingleParticle Soot Photometer (SP2), Geophysical Research Letters, 39(6), n/a-n/a, doi:10.1029/2012GL050905.

Sedlacek, A. J., E. R. Lewis, T. B. Onasch, A. T. Lambe, and P. Davidovits (2015), Investigation of Refractory Black Carbon-Containing Particle Morphologies Using the Single-Particle Soot Photometer (SP2), Aerosol Science and Technology, 49(10), 872-885, doi:10.1080/02786826.2015.1074978.

Shindell, D., et al. (2012), Simultaneously Mitigating Near-Term Climate Change and Improving Human Health and Food Security, Science, 335(6065), 183-189, doi:10.1126/science.1210026. Shrivastava, M., L. K. Berg, J. D. Fast, R. C. Easter, A. Laskin, E. G. Chapman, W. I. Gustafson, Y. Liu, and C. M. Berkowitz (2013), Modeling aerosols and their interactions with shallow cumuli during the 2007 CHAPS field study, Journal of Geophysical ResearchAtmospheres, 118(3), 1343-1360, doi:10.1029/2012jd018218.

Stevens, B., and G. Feingold (2009), Untangling aerosol effects on clouds and precipitation in a buffered system, Nature, 461(7264), 607-613.

Subramanian, R., C. A. Roden, P. Boparai, and T. C. Bond (2007), Yellow Beads and Missing Particles: Trouble Ahead for Filter-Based Absorption Measurements., Aerosol Science and Technology, 41(6), 630-637.

Thompson, J. E., N. Barta, D. Policarpio, and R. DuVall (2008), A fixed frequency aerosol albedometer, Opt. Express, 16(3), 2191-2205, doi:10.1364/OE.16.002191.

Wood, R. (2012), Stratocumulus Clouds, Monthly Weather Review, 140(8), 2373-2423, doi:doi:10.1175/MWR-D-11-00121.1.

Zhang, X., Y.-H. Lin, J. D. Surratt, and R. J. Weber (2013), Sources, Composition and Absorption Ångström Exponent of Light-absorbing Organic Components in Aerosol Extracts from the Los Angeles Basin, Environmental Science \& Technology, 47(8), 3685-3693, doi:10.1021/es305047b.

Zhang, X. L., Y. H. Lin, J. D. Surratt, P. Zotter, A. S. H. Prevot, and R. J. Weber (2011), Lightabsorbing soluble organic aerosol in Los Angeles and Atlanta: A contrast in secondary organic aerosol, Geophysical Research Letters, 38, doi:10.1029/2011gl049385. 


\section{Appendix A}

\section{AA workshop agenda}

January 20, 2016 (Wednesday)

8:30 am: Arrive at DOE for badging

Morning sessions will be in Room A-410

8:30 - 9:00 am: Coffee/Registration (full breakfast will be available at the hotel)

9:00 - 9:10 am: Welcome and logistics (DOE)

9:10 - 9:30 am: Brief introductions (1 min each)

- Name and Institution

- What you work on (two sentences)

- What is really difficult about what you are working on? (Related to workshop theme)

9:30 - 10:00 am: Ashley/Shaima/Dorothy:

- ASR Program Managers views on absorbing aerosols and the role of BER

- Possibilities, constraints, and path forward

- Role of this workshop to DOE, relationship to ACME

10:00 - 10:15 am: Coffee break

10:15 am - 12:15 pm: Plenary Session

- Plenary Presentation - Tami Bond (30 min, including questions)

- Overview of white papers synthesis - Chris Cappa (30 min)

- Plenary Discussion: Prioritize research areas identified in the white paper and during introduction - categorize the priorities and impediments into 'topic' areas

12:15 - 1:15 pm: Lunch Break (DOE Cafeteria)

Afternoon sessions will be in Rooms E-401 and G-209

1:15 - 1:30 pm: Reconvene in Room E-401

Outline Goals/Objectives for breakout sessions and assign breakout group membership and

introduce overarching Breakout Themes (subject to refinement based on Plenary discussion)

Theme 1: Bridging Measurement/Modeling Gaps

- Path forward to bridging the gap between point sensing (e.g., PAS, PSAP, SP2, etc.) and larger scale/column/global measurements (satellite, MFRSR, 4Star, lidar)?

- Path(s) forward on model scaling (e.g., Particle-resolved to bulk)

Theme 2: Knowledge gaps in atmospheric effects of absorbing aerosols

- What are the gaps in our understanding of how absorbing aerosols influence atmospheric stability, circulation, and, ultimately, cloud properties?

Theme 3: Emissions (flux) and/or Inventories (concentrations): sources, properties, and factors that affect these

- What are the observational/knowledge gaps that still persist in top-down and bottomup comparisons? 
1:30 - 2:30 pm: Breakout Session \#1

Green Working Group: (room E-401) - Led by Art;

Blue Working Group: (room G-209) - Led by Rao;

2:30 - 2:45 pm: Coffee Break (room E-401)

Breakout session chairs/rapporteur distill discussion findings

2:45 - 4:00 pm: Breakout Session \#1 continued

Green Working Group: (room E-401) - Led by Art

Blue Working Group: (room G-209) - Led by Rao

4:00 - 4:15 pm: Chair catch-up period (room E-401)

4:15 - 5:00 pm: Reconvene in room E-401

- Breakout session chairs/rapporteur distill discussion and upload to Google Drive

- Working Group Blue walks to E-401.

- Presentation by breakout discussion findings (Session Chairs)

- Outline plan for next day

6:00 pm: Dinner on your own at Green Turtle restaurant

January 21, 2016 (Thursday)

Morning: Plenary (Room A-410)

8:30 - 9:00 am: Check in/Coffee

9:00 - 9:30 am: Ashley/Shaima: Briefing for the day (Expectations / overall impressions so far)

- Outline Breakout Themes: Implementation

For the prioritized list of science questions identified during previous day's breakout sessions identify:

- What resources, time, and connections are vital for addressing knowledge gaps

- Connections with ARM/ASR instrument/modeling capabilities and requirements for additional resources

- Technical/scientific roadblocks that must be overcome

9:30 - 11:00 am: Breakout Session \#2

- Purple Working Group: (room A-410)

- Red Working Group: (room G-209)

11:00 - 11:15 am: Coffee break (room A-410)

Breakout session chairs/rapporteur distill discussion findings and upload to Google Drive

11:15 am - 12:30 pm: Reconvene in room A-410

Merge topics across the groups

Attendees review and add comments to breakout session summaries

12:30 - 1:30 pm Lunch on your own at the Cafeteria 
1:30 - 2:30 pm Reconvene in Room E-401 for wrap up and next steps (Ashley/Shaima)

2:30 pm: Transportation to airports /end of the meeting

$* * * * * * * * * * * * * * * * * * * * * * * * * * * * * * * * * *$ End of Day $2^{* * * * * * * * * * * * * * * * * * * * * * * * * * * * * * * * * * *}$

2:30 - 5:00 pm: Assemble AA workshop Writing Team (Co-Chairs and Writing Team) (J-108)

Draft workshop highlights and summary

Outline Final Report writing timeline and writing assignments 


\section{Appendix B}

\section{Break Out Groups}

\author{
Green Team (E-401) \\ Art Sedlacek (discussion leader) \\ Allison McComiskey Rapporteur) \\ Dubey Manvendra (Rapporteur) \\ Pat Arnott \\ Yan Feng \\ Connor Flynn \\ Mary Gilles \\ Tim Onasch \\ Rahul Zaveri
}

\author{
Blue Team (G-209) \\ Rao Kotamarthi (discussion leader) \\ Allison Aiken (Rapporteur) \\ Chris Cappa (Rapporteur) \\ Tami Bond \\ Rich Ferrare \\ Mark Flanner \\ Ernie Lewis \\ Nicole Riemer \\ Stephen Springston
}

\section{Participant listings}

\author{
Allison Aiken \\ W. Pat Arnott \\ Tami Bond \\ Christopher Cappa \\ Manvendra Dubey \\ Yan Feng \\ Rich Ferrare \\ Mark Flanner \\ Connor Flynn \\ Mary Gilles \\ Rao Kotamarthi \\ Ernie Lewis \\ Allison McComiskey \\ Tim Onasch \\ Nicole Riemer \\ Arthur Sedlacek \\ Stephen Springston \\ Rahul Zaveri
}

\author{
LANL \\ U. of Nevada \\ U. of Illinois/Urbana \\ U. California/Davis \\ LANL \\ ANL \\ NASA Langley \\ $U$. of Michigan \\ PNNL \\ LBL \\ ANL \\ BNL \\ NOAA \\ Aerodyne \\ U. of Illinois/Urbana \\ BNL \\ BNL \\ PNNL
}

\section{Observers:}

Earth System Modeling program manager

Director of Climate and Environment Sciences Div. ARM Climate Research Facility program manager ARM Aerial Facility program manager 


\section{Appendix C}

\section{Acronyms}

AA

AAOD

AIR-MISR

ANL

AOD

$\mathrm{ACl}$

AERONET

AMF

ARI

ARM

ASR

BB

BBOP

$B C$

BNL

$\mathrm{BrC}$

BRW

BER

CCN

CESD

CIP

CIN

CHARMS

CLAP

DOE

EARLINET

ENA

ICCP

LANL

LBL

Lidar

LES

MD

MFRSR

MODIS

$\mathrm{nm}$

NASA

NOAA

PAX

PAS

PASS-3

PNNL

POA

PSAP

PTI
Absorbing Aerosol

Aerosol Absorption Optical Depth

Airborne Multi-angle Imaging SpectroRadiometer

Argonne National Laboratory

Aerosol Optical Depth

Aerosol-Cloud Interactions

Aerosol Robotic Network

ARM Mobile Facility

Aerosol-Radiation Interactions

Atmospheric Radiation Measurement

Atmospheric Systems Research

Biomass Burning

Biomass Burning Observation Project

Black Carbon

Brookhaven National Laboratory

Brown Carbon

Barrow Alaska Observation site

Biological and Energy Research

Cloud Condensation Nuclei

Climate and Environmental Sciences Division

Column Intensive Properties

Convective Inhibition

$\mathrm{CH} 4$ Atmospheric Remote Monitoring

Continuous Light Absorption Photometer

Department of Energy

European Aerosol Research Lidar Network

Eastern North Atlantic

Intergovernmental Panel on Climate Change

Los Alamos National Laboratory

Lawrence Berkeley Laboratory

light detection and ranging

Large Eddy Simulation

Mineral Dust

Multi-filter Rotating Shadowband Radiometer

Moderate Resolution Imaging Spectroradiometer

Nanometer $\left(10^{-9} \mathrm{~m}\right)$

National Aeronautics and Space Administration

National Oceanographic and Atmospheric Administration

Photoacoustic Extinctiometer

Photoacoustic Spectrometer

Photoacoustic Absorption Soot Spectometer

Pacific Northwest National Laboratory

Primary Organic Aerosol

Particle Soot Absorption Photometer

Photothermal Interferometer 


OA
OC
OMAERUV
OMI
RH
SKYNET
SSA
SGP
SOA
SSEC
TAP
UAS

Organic Aerosol

Organic Carbon

OMI/Aura Aerosol Optical Thickness \& Single Scattering

Ozone Monitoring Instrument

Relative Humidity

Observation network interaction

Single Scattering Albedo

Southern Great Plains

Secondary Organic Aerosol

Space Science and Engineering Center

Tri-color Absorption Photometer

Unmanned Aerial System 